\title{
USO DE FERTILIZANTES NITROGENADOS NA CULTURA DO MILHO APÓS CULTIVO DE TREMOÇO BRANCO (Lupinus albus) EM PODZÓLICO VERMELHO AMARELO LATOSSÓLICO DISTRÓFICO
}

NAGIB JORGE MELÉM JÚNIOR

Engenhieiro Agrônomo

Orientador: Prof. Dr. JAIRO ANTÔNIO MAZZA

Dissertação apresentada à Escola Superior de Agricultura "Luiz de Queiroz", Universidade de São Paulo, para obtenção do título de Mestre em Agronomia, Área de Concentração: Solos e Nutrição de Plantas.

P I R A C I C A B A

Estado de São Paulo - Brasil

Fevereiro - 1998 
Melém Júnior, Nagib Jorge

Uso de fertilizantes nitrogenados na cultura do milho após cultivo de tremoço branco (Lupinus albus) em podzólico vermelho amarelo latossólico distrófico / Nagib Jorge Melém Júnior. - P Piracicaba, 1998.

$46 \mathrm{p}$.

Dissertaçāo (mestrado) - - Escola Superior de Agricultura Luiz de Queiroz, 1998.

Bibliografia.

1. Adubo verde 2. Análise-química 3. Enxofre 4. Fertilizante nitrogenado 5. Milho 6. Podzolico vermelho-amarelo 7. Solo 8. Tremoço I. Título

CDD 633.15 
USO DE FERTILIZANTES NITROGENADOS NA CULTURA DO MILHO APÓS CULTIVO DE TREMOÇO BRANCO (Lupinus albus) EM PODZÓLICO VERMELHO AMARELO LATOSSÓLICO DISTRÓFICO

NAGIB JORGE MELÉM JÚNIOR

Aprovada em: 30.03 .1998

Comissão julgadora:

Prof. Dr. Jairo Antônio Mazza

ESALQ/USP

Prof. Dr. Godofredo Cesar Vitti ESALQ/USP

Prof. Dr.Salatiér Buzzetti FEIS/UNESP

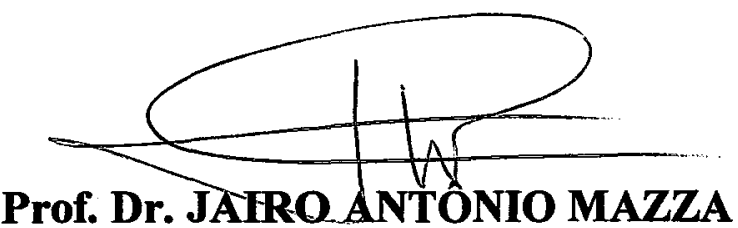

Orientador 
A meus pais, Nagib (in memoriam) e Josa;

A meus irmãos e irmãs;

A meu irmão e segundo pai, Paulo;

À Lolita, Filomena e Maria Joana

A meus sogros José Ribamar (in memoriam) e Raimunda.

\section{OFEREÇO}

A Alice e Fernando, por toda ajuda, amor e carinho recebidos. 


\section{AGRADECIMENTOS}

Em primeiro lugar a Deus por estar presente em todos os momentos; colocando em minha vida todos os que contribuíram para a realização desta obra.

Ao Prof. Dr. Jairo Antônio Mazza, pela amizade, dedicação e orientação;

À EMBRAPA - CPAF/Amapá pela oportunidade concedida;

À Coordenação de Aperfeiçoamento de Pessoal de Nível Superior (CAPES), pela bolsa de estudo concedida;

À Escola Superior de Agricultura "Luiz de Queiroz" através de seus professores pelos ensinamentos recebidos;

Ao Conselho de Curso de Pós Graduação em Solos e Nutrição de Plantas, na pessoa de seu Coordenador, Prof. Dr. Francisco Antonio Monteiro pela oportunidade e auxílio prestado;

Aos membros da Comissão Julgadora pelas sugestões apresentadas;

Aos Departamentos de Agricultura, Ciência do Solo, Engenharia Rural, e Zootecnia, pelas facilidades concedidas;

Ao Prof. Dr. Carlos Tadeu dos Santos Dias pelo valioso auxílio na análise estatística dos experimentos;

Aos Profs. Godofredo Cesar Vitti, José Laércio Favarin e Pedro Henrique de Cerqueira Luz (FZEA/USP) pelas sugestões e auxílio prestados;

Aos acadêmicos Emerson Gilberto Briske e Cláudio de Almeida Kehdi, aos Eng ${ }^{\circ}$ Agrônomos Jorge Fávaro Gomes, Lucas Gutierrez, e ao Técnico Agrícola Jair Ferrer da Silva pelo apoio fundamental durante o desenvolvimento dos trabalhos de campo;

Ao Doutorando em Fitotecnia Oscar Smiderle, pelo auxílio na realização das análises de sementes; 
À Mestranda em Agrometeorologia Zilda de Fátima Mariano pelo auxílio na elaboração do balanço hídrico;

Aos funcionários dos laboratórios do Departamento de Ciência do Solo: Anderson Luiz Scarazati, Antônio Carlos Ferreira, Eleusa Cecília Basse, João Álvaro Granja, José Iremar da Silva, José Luiz Vicente, Leandro Goia, Luciano Dias Ferraz, Luis Eduardo Bombo, Luiz Antônio Silva Jr., Marcos Antônio Fabiano de Camargo, Vanda Zancheta, Wladimir José Rosignolo, estagiária Elaine Pozzani e Cleusa Pereira Cabral (CENA/USP) pelo auxílio na realização das análises;

Aos colegas, funcionários da EMBRAPA - CPAF/Amapá, em especial a Leda dos Anjos do Setor de Recursos Humanos pelo apoio constante durante a realização deste curso;

Aos colegas do Curso de Pós Graduação em Solos e Nutrição de Plantas;

Ao colega Miguel Cooper pelo auxílio na confecção do Summary;

À Sra. Maria Sueli Minatel Mazza pela revisão ortográfica;

Às Bibliotecárias Eliana M. Garcia Sabino e Kátia M. de Andrade Ferraz pela revisão das referências bibliográficas;

Às Auxiliares de Bibliotecárias Luzia Fátima dos Santos Possato e Silvana Cristina Nascimento de Oliveira pelo excelente atendimento prestado;

À Beliza, Edson, Josef, Lucietta, Marcos, Michelle, Oscarlina, Sávio, Tadeu, e Rodrigo, pela amizade e companheirismo;

A Cláudio e Silvia, Silas e Marilene, Tomé e Ana, Jorge Segóvia e Jaci, pela amizade e ajuda durante a realização do curso A todos aqueles que tenham contribuído para a realização dessa obra. 


\section{SUMÁRIO}

LISTA DE FIGURAS...................................................................................ii

LISTA DE TABELAS..................................................................................ii

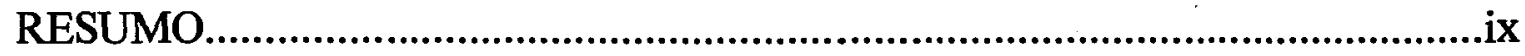

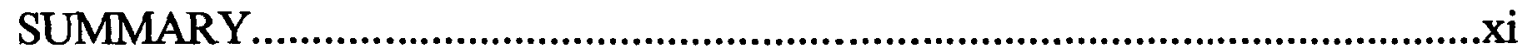

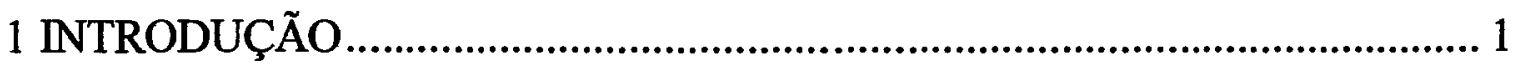

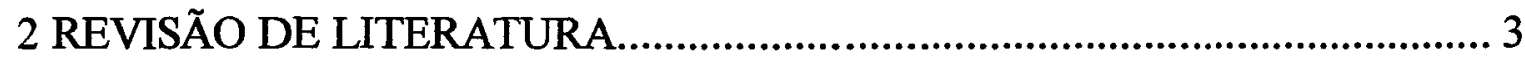

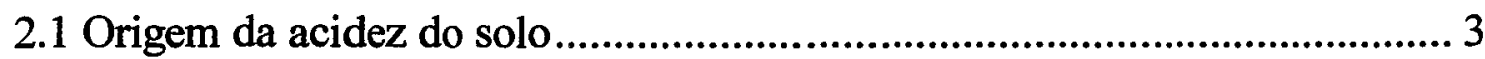

2.2 Acidificação do solo por fertilizantes nitrogenados.....................................5

2.3 Influência da lixiviação de nutrientes na acidificação do solo.......................7

2.4 Efeito da adubação verde com tremoço sobre a produção de milho ........... 10

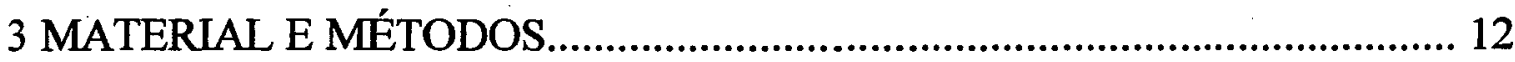

3.1 Caracterização do solo da área experimental.......................................... 12

3.2 Balanço hídrico da região durante o experimento................................... 12

3.3 Avaliação da produtividade de grãos e de matéria seca total do milho...... 15

3.4 Amostragem do solo e avaliação dos atributos químicos ............................ 15

3.5 Avaliação do tremoço (Lupinus albus) presente na área experimental e

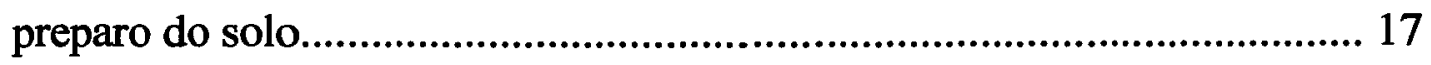

3.6 Instalação e condução do experimento ...................................................... 17

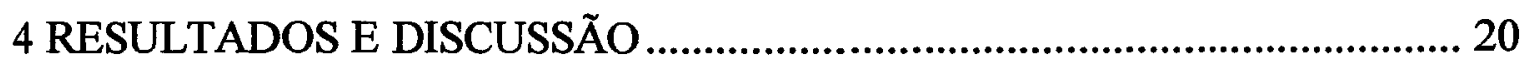

4.1 Produtividade de grãos e de matéria seca do milho ................................. 20 
4.2 Modificação dos atributos químicos do solo em função dos tratamentos

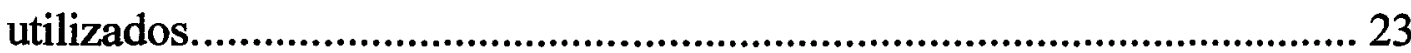

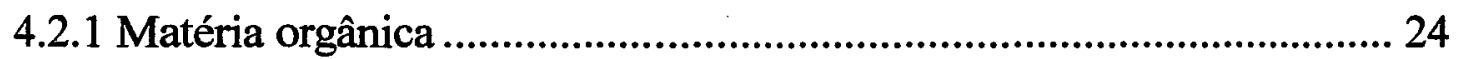

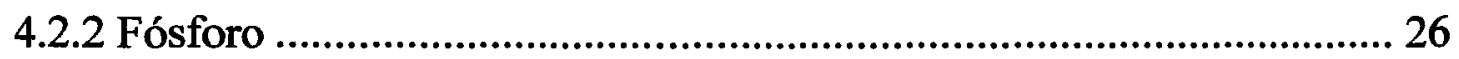

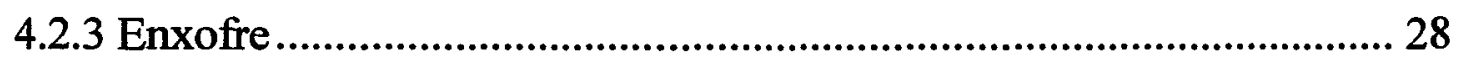

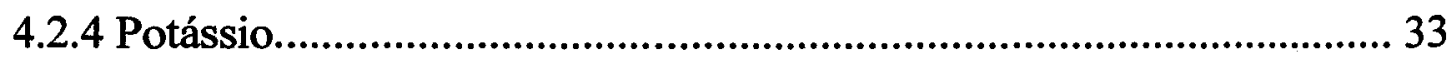

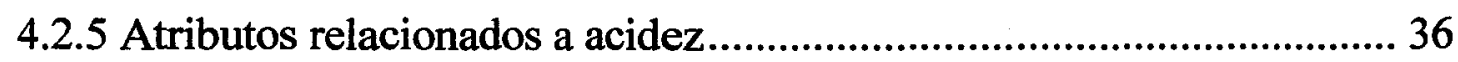

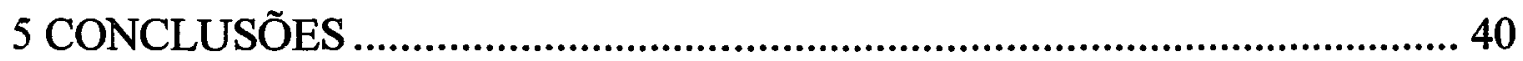

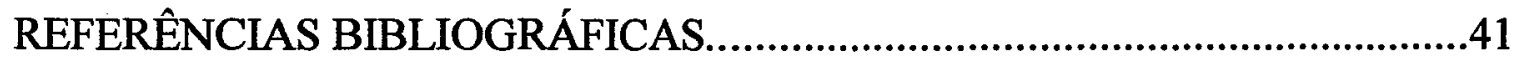




\section{LISTA DE FIGURAS}

Páginas

1 Precipitação mensal no período de Set/96 a Ago/97......................................14

2 Extrato do balanço hídrico decendial no período de Set/96 a Ago/97.............14

3 Produtividade média de grãos em cada tratamento........................................21

4 Produtividade média de matéria seca total em cada tratamento......................22

5 Teores de matéria orgânica para a interação época $\mathrm{x}$ profundidade.................25

6 Teores de fósforo para a interação época $\mathrm{x}$ profundidade...............................27

7 Teores de fósforo para a interação época x fertilizante..................................28

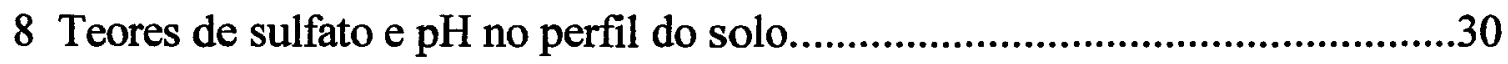

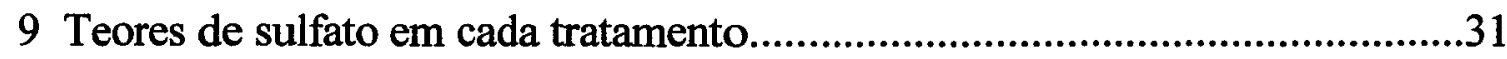

10 Teores de sulfato ao longo do perfil nos tratamentos com sulfato de amônio e nitrato de amônio.......................................................................32

11 Potássio na interação época x profundidade …..........................................34

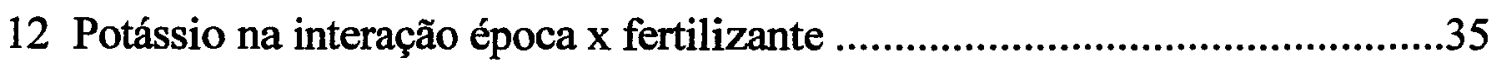

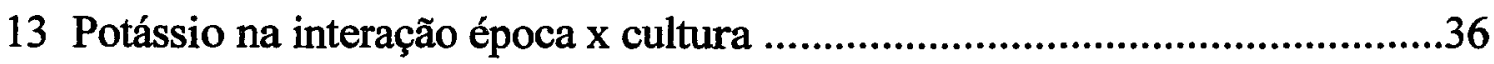

14 Saturação por bases e pH ao longo do perfil do solo.....................................39

15 Soma de bases e $\mathrm{pH}$ ao longo do perfil do solo.........................................39

16 Saturação por alumínio e pH ao longo do perfil do solo..............................39 


\section{LISTA DE TABELAS}

Páginas

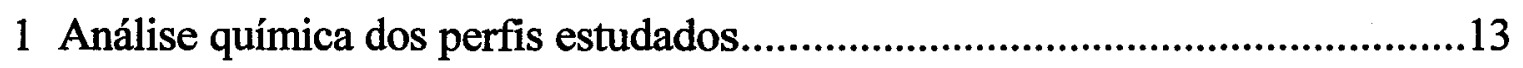

2 Quantidade de adubos aplicados por parcela em cada cobertura.....................18

3 Médias da produtividade, matéria seca total e eficiência obtidas em

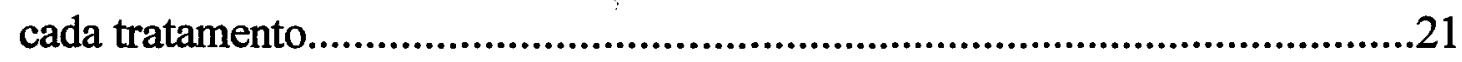

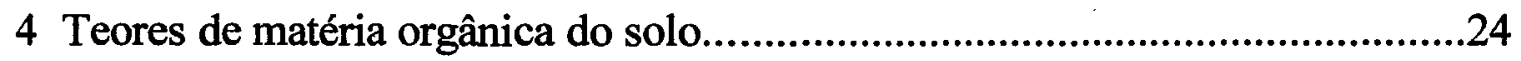

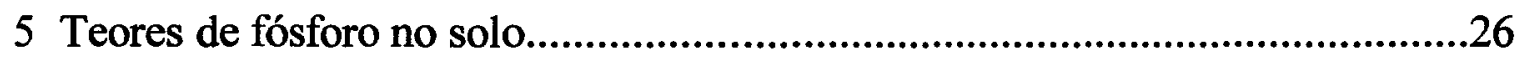

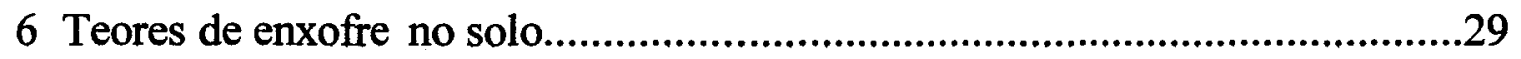

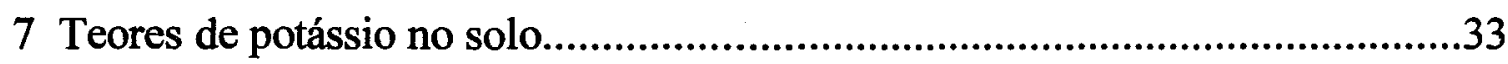

8 Atributos relacionados a acidez nas interações estudadas..............................38 
USO DE FERTILIZANTES NITROGENADOS NA CULTURA DO MILHO APÓS CULTIVO DE TREMOÇO BRANCO (Lupinus albus) EM PODZÓLICO VERMELHO AMARELO LATOSSÓLICO DISTRÓFICO

\author{
Autor: NAGIB JORGE MELÉM JÚNIOR \\ Orientador: Prof. Dr. JAIRO ANTÔNIO MAZZA
}

\title{
RESUMO
}

O crescimento populacional tem exigido cada vez mais a utilização de novas áreas agrícolas e/ou a exploração tecnificada de áreas já existentes de modo a incrementar a produção de alimentos, fibras ou energia renovável. Este fato vem fornecendo à atividade agrícola um caráter empresarial, mostrando que elevadas produções, em curto espaço de tempo, dependem diretamente do incremento do grau de tecnificação. Em contrapartida, o uso de genótipos com uma capacidade de extração elevada, e a utilização de fertilizantes nitrogenados, com alto índice de acidez, podem potencializar problemas como a acidificação dos solos, promovendo reduções nas produtividades e causando prejuízos ao produtor.

A quantificação dos fatores de acidificação do solo se reveste de grande importância para a escolha e utilização econômica de corretivos e fertilizantes, de modo a promover um balanço positivo através do uso desses insumos.

Este trabalho teve por objetivo a determinação da influência de dois fertilizantes nitrogenados sulfato e nitrato de amônio nos atributos químicos do solo, sendo realizado um ensaio em solo de textura média, que foi classificado como Podzólico Vermelho Amarelo Latossólico Distrófico, utilizando-se a cultura 
do milho e avaliando-se as modificações ocorridas nos atributos do solo através de sua análise química, como também a produtividade e a produção de matéria seca total do milho. O solo utilizado foi previamente cultivado para produção de sementes de tremoço (Lupinus albus).

Para avaliação dos atributos químicos do solo foram realizadas amostragens nas profundidades de 0-20, 20-40, 40-60, 60-80 e 80-100 cm, antes e após o cultivo do milho. Os atributos avaliados foram: $\mathrm{pH}$, teor de matéria orgânica, cálcio, magnésio, enxofre, fósforo, potássio, alumínio, soma de bases, capacidade de troca catiônica, saturação por bases e saturação por alumínio.

Adotou-se o delineamento experimental de blocos aleatorizados com 5 repetições, em esquema fatorial $2 \times 5 \times 6$, possuindo 2 épocas de amostragem, 5 profundidades de amostragem e 6 tratamentos. Os tratamentos adotados foram formados pela combinação dos fatores: adubação nitrogenada de cobertura com sulfato de amônio ou nitrato de amônio e a cultura do milho, onde cada fator estava presente nos níveis 0 e 1 (ausência e presença).

Os resultados obtidos permitiram as seguintes conclusões:

- A adubação nitrogenada do milho, com nitrato de amônio e/ou sulfato de amônio no Podzólico Vermelho Latossólico, incrementou a produção da cultura apesar da adubação verde prévia;

- O nitrato e o sulfato de amônio apresentaram-se igualmente eficientes no fornecimento de nitrogênio para a cultura do milho;

- As fontes nitrogenadas adotadas não causaram acidificação significativa do solo após uma safra da cultura do milho;

- A utilização do sulfato de amônio resultou em maiores teores de enxofre no solo quando comparado ao nitrato de amônio. 
USE OF NITROGEN FERTILIZERS IN CORN AFTER CROP OF WHITE LUPINE (Lupinus albus) ON A TYPIC PALEUDULT

\author{
Author: NAGIB JORGE MELÉM JÚNIOR \\ Adviser: Prof. Dr. JAIRO ANTÔNIO MAZZA
}

\title{
SUMMARY
}

The population growth has imposed the use of new agricultural areas and/or the technified exploitation of already existing areas in a way to increase the food, fiber or renewable energy production. This fact has given an business connotation to the agricultural activity, showing that high yields in a short period of time depend directly of the increase in the technification degree. On the other hand, the use of high extraction capacity genotypes and the use of nitrogen fertilizers, with a high acidity index, can potentialize problems as soil acidification, promoting yield reductions and losses to the farmer.

The quantification of the soil acidification factors is of great importance for the choice and economical use of correctives and fertilizers, in a way to promote a positive balance through the use of these inputs.

The purpose of this work was to determine the level of influence of two nitrogen fertilizers, ammonium sulfate and ammonium nitrate, in the soil chemical attributes. An experiment was performed on a medium textured soil classified as a Typic Paleudult. Corn was used and the modifications that occurred in the soil chemical attributes as well as yield and total dry matter were evaluated. The soil had been previously used for the production of white lupine (Lupinus albus) seeds. 
To evaluate the soil chemical attributes, the soil was sampled at the depths of $0-20,20-40,40-60,60-80$, and $80-100 \mathrm{~cm}$, before and after the corn cultivation. The evaluated attributes were: $\mathrm{pH}$, organic matter content, calcium, magnesium, sulfur, phosphorous, potassium, aluminum, sum of bases, CEC, base saturation, and aluminum saturation.

A random block experimental design with 5 repetitions, a $2 \times 5 \times 6$ factorial scheme, 2 sampling periods, 5 sampling depths and 6 treatments, was adopted. The adopted treatments were formed by the combination of the factors: cover nitrogen fertilization with ammonium sulfate or ammonium nitrate and corn, where each factor was present in the levels 0 and 1 (absence and presence).

The results permitted to reach the following conclusions:

- The nitrogen fertilization of corn with ammonium nitrate and/ or ammonium sulfate on the Typic Paleudult, increased the crop's production in spite of the previous green manure;

- Ammonium nitrate and ammonium sulfate were equally efficient in the supply of nitrogen to corn;

- The adopted nitrogen sources did not cause acidification of the soil after one corn cycle;

- The use of ammonium sulfate resulted in higher soil sulfur contents when compared to ammonium nitrate. 


\section{INTRODUÇÃO}

Os inúmeros trabalhos desenvolvidos sobre acidez do solo tratam freqüentemente da determinação de doses econômicas de corretivos, da aplicação eficiente dos mesmos ou dos métodos para estimativa da necessidade de calcário, preocupando-se muito pouco com os fatores que provocam a acidez do solo, fatores esses que são de fundamental importância para o uso do solo pelas plantas, influenciando sobremaneira no rendimento agrícola adequado em termos de alimentos, fibras ou energia.

Nas regiões tropicais úmidas sabe-se que os fatores que causam a acidez são, principalmente, a pluviosidade e a distribuição pluviométrica (lixiviação de bases e adição de íons hidrogênio), a extração de bases pelas culturas, as trocas iônicas na região da rizosfera, o uso de fertilizantes nitrogenados com índice de acidez elevado, além de fatores da própria formação do solo.

A quantificação dos fatores da acidificação do solo reveste-se de grande importância para a escolha e utilização econômica de corretivos e fertilizantes, de modo a promover um balanço positivo através do uso desses insumos. Particularmente, na região Norte do Brasil o consumo de fertilizantes e corretivos é pequeno, devido ao baixo poder aquisitivo do produtor rural e aos preços proibitivos dos insumos em função do frete, provocando baixa produtividade das culturas e danos ambientais em função da derrubada e queima de novas áreas de floresta para a agricultura. 
Este trabalho teve por objetivo a determinação da influência de dois fertilizantes nitrogenados nos atributos químicos do solo, sendo realizado um ensaio em solo de textura média, utilizando-se a cultura do milho, e avaliando-se as modificações ocorridas no solo através de sua análise química, como também a produtividade de grãos e a produção de matéria seca total do milho. 


\section{REVISÃO DE LITERATURA}

\subsection{Origem da acidez do solo}

Os solos tropicais são normalmente ácidos, seja pela ocorrência de precipitação suficientemente alta para lixiviar quantidades apreciáveis de bases trocáveis do solo, seja pela ausência de minerais primários e secundários responsáveis pela reposição dessas bases (Vitti \& Prochnow, 1996). Além da ocorrência natural da acidez do solo pelos motivos anteriormente expostos, as práticas agrícolas também podem acentuar o problema. Quevedo Camacho (1995) citou que embora o problema da acidificação do solo pelos fertilizantes nitrogenados seja reconhecido há muito tempo, ainda não se tem informações precísas sobre o papel da planta como agente modificador desse processo. A dificuldade de se avaliar o efeito da cultura na reação do solo aumenta quando se considera que o padrão de absorção de cátions e ânions entre plantas de diferentes espécies ou até da mesma espécie pode sofrer amplas variações.

Cajuste (1977) citou que o $\mathrm{pH}$ do solo afeta a solubilidade de muitos elementos essenciais às plantas e também de elementos tóxicos. Afeta também as propriedades de intercâmbio de cátions' e ânions do solo e as atividades dos microorganismos do solo. Para a formação de solos ácidos requer-se suficiente precipitação para lixiviar, lavar ou eliminar os sais carbonatados a uma velocidade maior do que a de sua formação.

Segundo Fassbender \& Bornemisza (1987), a acidificação progressiva que se apresenta de maneira especial nos solos das áreas tropicais 
úmidas, particularmente quando se pratica uma agricultura intensiva, deve-se à troca contínua de bases trocáveis $(\mathrm{Ca}, \mathrm{Mg}, \mathrm{K} \mathrm{e} \mathrm{Na})$ por íons $\mathrm{H}$ e $\mathrm{Al}$. Esta troca resulta da percolação de água, da extração das bases trocáveis e do uso de adubos de caráter ácido.

Quaggio (1986) relatou que a acidificação consiste na remoção das bases trocáveis para camadas profundas do solo; para isso ocorrer torna-se necessária a introdução de íons com carga negativa, que tem facilidade de se movimentar através do fluxo descendente de água, ligando às bases e promovendo a sua movimentação. Na natureza, esses ânions são adicionados na solução do solo através da mineralização da matéria orgânica, com a qual há liberação de íons $\mathrm{NO}_{3}^{-}, \mathrm{SO}_{4}{ }^{2-} \mathrm{e} \mathrm{Cl}^{-}$, e ainda através de reações químicas, como a dissociação do gás carbônico e a nitrificação.

$\mathrm{O} \mathrm{CO}_{2}$ dissocia-se segundo a reação (1):

$$
\mathrm{CO}_{2}+\mathrm{H}_{2} \mathrm{O} \leftrightarrows \mathrm{H}^{+}+\mathrm{HCO}_{3}^{-} \downarrow
$$

Essa reação, além de liberar o íon $\mathrm{H}^{+}$, libera também o íon bicarbonato, que arrastará bases em profundidade.

A nitrificação consiste na oxidação do nitrogênio a partir do amônio até nitrato, a qual é realizada pelas bactérias dos gêneros Nitrosomonas (2) e Nitrobacter (3):

$$
\begin{gathered}
2 \mathrm{NH}_{4}^{+}+3 \mathrm{O}_{2} \rightarrow 2 \mathrm{NO}_{2}^{-}+4 \mathrm{H}^{+}+2 \mathrm{H}_{2} \mathrm{O} \\
2 \mathrm{NO}_{2}^{-}+\mathrm{O}_{2} \rightarrow 2 \mathrm{NO}_{3} \downarrow
\end{gathered}
$$

Do mesmo modo que a dissociação do $\mathrm{CO}_{2}$, a nitrificação libera íons $\mathrm{H}^{+}$e ânions, que no caso é o nitrato. Quevedo Camacho (1995) comentou que o processo de nitrificação é de grande importância agronômica, já que o 
nitrato produzido pode ser absorvido pelas plantas ou perde-se no solo por lixiviação. $\mathrm{O}$ autor citou ainda que a oxidação do amônio a nitrato resulta na liberação de íons $\mathrm{H}^{+}$que tendem a acidificar o solo e há muito tempo vem merecendo atenção da pesquisa. A nitrificação torna-se ainda mais importante em solos cultivados onde as culturas recebem adubos nitrogenados contendo fontes amoniacais ou amídicas.

No caso dos fertilizantes, tem-se que lembrar, ainda, que eles carregam nas suas fórmulas outros ânions, como sulfato e cloreto, que após a solubilização também ficam livres na solução do solo para arrastarem as bases.

\subsection{Acidificação do solo por fertilizantes nitrogenados}

A exploração do solo por culturas de alta produtividade exige o emprego de quantidades elevadas de fertilizantes, dentre os quais os nitrogenados se destacam por fornecerem um dos nutrientes mais exigidos pelos vegetais. Os fertilizantes nitrogenados, entretanto, dependendo da sua composição química, podem reagir com o solo da acidez até a alcalinidade (Quevedo Camacho (1995).

A capacidade de acidificação de um fertilizante nitrogenado é representada pelo índice de acidez (quantidade de $\mathrm{CaCO}_{3}$ necessária para neutralizar a acidez originada pelo uso de $100 \mathrm{~kg}$ do fertilizante), para o sulfato de amônio o índice de acidez é 110, enquanto que para o nitrato de amônio o índice é de 62 (Vitti \& Prochnow, 1996).

Resultados de estudos desenvolvidos em vários países têm demonstrado que o uso contínuo de fontes nitrogenadas amoniacais por períodos prolongados de tempo tem ocasionado a elevação da acidez do solo. Nesses estudos tem sido constatado que o sulfato de amônio é a fonte nitrogenada com maior poder de acidificação do solo. Diversos autores consideram que a acidificação decorrente do uso de fertilizantes nitrogenados é uma das maiores 
causas da perda do potencial produtivo dos solos. (Mahler et al., 1985; Obi, 1989; Rasmussen \& Rohde, 1989; Stumpe \& Vlek, 1991 e Wolcott et al., 1965.).

No Brasil também há bastante tempo a acidificação do solo pelos adubos nitrogenados vem despertando a atenção dos pesquisadores. Neves et al. (1960) estudaram em campo o efeito do salitre do Chile, da uréia e do sulfato de amônio, sempre na dosagem de $80 \mathrm{~kg} \mathrm{ha}^{-1}$ de $\mathrm{N}$, sobre o $\mathrm{pH}$ de um solo da Estação Experimental de Campinas. No início do experimento e três anos após a última adubação, foram retiradas amostras de terra, objetivando a determinação do $\mathrm{pH}$. Para os tratamentos sem adubação nitrogenada o $\mathrm{pH}$ foi de 6,50; para os tratamentos com salitre do Chile, uréia e sulfato de amônio foram respectivamente de 5,91, 5,61 e 5,07. Concluíram que o salitre do Chile atenuou a acidificação do solo, enquanto que o maior efeito acidificante foi provocado pelo sulfato de amônio, que fez reduzir o pH em aproximadamente 1,5 unidade.

Moraes (1974), em experimento com cafeeiros em vasos, aplicou quatro fontes nitrogenadas, observando que, com exceção do salitre do Chile, os fertilizantes apresentaram acentuada ação acidificante sobre o solo, cuja intensidade obedeceu à seguinte ordem: sulfato de amônio > nitrato de amônio > uréia.

Hiroce et al. (1977) estudaram o efeito acidificante de quatro fertilizantes nitrogenados no solo e sua influência em plantas de cafeeiro no campo verificando que o sulfato de amônio, a uréia e o nitrocálcio possuíram ação acidificante no solo, obedecendo à seguinte ordem: sulfato de amônio $>$ uréia $\approx$ nitrocálcio > salitre do Chile. A acidificação causada pelo sulfato de amônio, uréia e nitrocálcio causou a elevação dos teores de manganês nas folhas.

Kiehl et al. (1981) estudaram, em ensaio de laboratório, o efeito acidificante do sulfato de amônio, do nitrato de amônio e da uréia em solos de diferentes texturas, verificando que o grau de acidificação não teve correlação 
com a textura; entretanto, os solos com maiores valores de $\mathrm{pH}$ foram os que mais se acidificaram, sendo que o maior decréscimo observado foi de 0,7 unidade de $\mathrm{pH}$, para o sulfato de amônio. $\mathrm{O}$ poder de acidificação dos adubos obedeceu à seguinte ordem: sulfato de amônio $=$ nitrato de amônio $>$ uréia .

Em um experimento com milho, fontes e doses de adubos nitrogenados, em vasos, Mello \& Arzolla (1983) estudaram a acidificação do solo e os efeitos residuais após a primeira e a segunda colheita, verificando que após a primeira colheita de milho a uréia praticamente não acidificou o solo, o nitrato de amônio teve um pequeno efeito e o sulfato de amônio um efeito mais pronunciado. Após a segunda colheita, a uréia e o nitrato de amônio elevaram muito pouco a acidez potencial do solo, enquanto o sulfato de amônio utilizado na dose de $120 \mathrm{~kg} \mathrm{ha}^{-1}$ ano $^{-1}$ provocou o decréscimo do $\mathrm{pH}$ de 4,7 para 3,9 e a elevação da acidez potencial em $10 \mathrm{mmol}_{\mathrm{c}} \mathrm{dm}^{-3}$.

Em experimento de laboratório com amostras de Latossolo Vermelho Escuro tratadas e não tratadas com $\mathrm{Ca}(\mathrm{OH})_{2}$, com a finalidade de verificar o efeito do sulfato de amônio e da uréia na acidificação, Mello et al. (1986) concluíram que tanto a uréia quanto o sulfato de amônio tenderam a reduzir o pH do solo, sendo o efeito do segundo mais intenso.

\subsection{Influência da lixiviação de nutrientes na acidificação do solo}

Muito pouca informação existe em relação às perdas de nutrientes por lixiviação experimentadas pelos solos tropicais. Ainda que tais perdas sejam, em geral, consideradas elevadas, as quantidades variam consideravelmente com o volume anual de água perdida pela drenagem profunda, com as propriedades do solo e com o tipo de cultivo. Na Colômbia, em solos Andepts sob elevada precipitação, foram detectadas elevadas perdas de nitratos, cálcio e magnésio, equivalentes a aproximadamente $225 \mathrm{~kg} \mathrm{ha}^{-1}$ de $\mathrm{N}, 827 \mathrm{~kg} \mathrm{ha}^{-1}$ de Ca e 242 $\mathrm{kg} \mathrm{ha}^{-1}$ de Mg (Sánchez, 1981). 
Raij (1986) relatou que a lixiviação de íons através do solo é uma das principais causas de perdas de nutrientes e de acidificação do solo. Os principais elementos sujeitos a processos de lixiviação, em quantidades elevadas, são o nitrogênio, o enxofre, o cloro, o cálcio, o magnésio, o potássio e o sódio. Os ânions mais lixiviados são $\mathrm{NO}_{3}^{-}, \mathrm{Cl}^{-}$e $\mathrm{SO}_{4}{ }^{2-}$, e os cátions $\mathrm{Na}^{+}, \mathrm{K}^{+}, \mathrm{Ca}^{2+}$ e $\mathrm{Mg}^{2+}$. $\mathrm{A}$ lixiviação total de bases depende dos ânions acompanhantes, e as perdas de um cátion, por exemplo o potássio, dependem dos teores de cátions complementares adsorvidos ao complexo de troca.

Segundo Reichardt (1986), a lixiviação dos íons através do solo é uma das principais causas de perdas de nutrientes e contribui em muito para a acidificação do solo.

Ritchey et al. (1980) determinaram em colunas de solo o movimento de bases utilizando $\mathrm{CaCO}_{3}, \mathrm{CaSO}_{4}$ e $\mathrm{CaCl}_{2}$, adicionando água correspondente a $1.200 \mathrm{~mm}$, verificaram que com o cloreto o Ca foi lixiviado até $180 \mathrm{~cm}$, com o sulfato até $75 \mathrm{~cm}$ e com o carbonato somente $25 \mathrm{~cm}$, observando que o uso de sulfato provocou decréscimos na saturação por alumínio e incrementou o $\mathrm{pH}$ do solo em profundidade.

Dal Bó et al. (1986) obtiveram resultados semelhantes, quando realizaram experimento em colunas com o objetivo de estudar os efeitos da adição de diferentes fontes de cálcio sobre a movimentação de bases no solo. Os autores utilizaram diferentes doses e profundidades de aplicação de três fontes de cálcio, $\mathrm{CaCO}_{3}, \mathrm{CaSO}_{4}$ e $\mathrm{CaCl}_{2}$, seguidos de um período de lixiviação e do cultivo de mudas de duas variedades de cana-de-açúcar. Após a análise das soluções não se observou movimentação de $\mathrm{Ca}$ nos tratamentos que receberam apenas $\mathrm{CaCO}_{3}$, confirmando sua baixa mobilidade no solo. A movimentação de bases foi muito intensa com o uso de $\mathrm{CaCl}_{2}$ e intermediária com $\mathrm{CaSO}_{4}$. A solubilidade dos 
compostos adicionados parece ter sido o principal fator responsável pela mobilidade diferencial de bases no solo.

Raij et al. (1982) analisaram durante cinco anos amostras de solo de um ensaio de calagem em milho, instalado em um solo Podzólico VermelhoAmarelo; inicialmente foram aplicadas $0,3.000,6.000 \mathrm{e} 9.000 \mathrm{~kg} \mathrm{ha}^{-1}$ de calcário dolomítico com PN de $81 \%$ e PRNT de 59\%. Analisaram-se nas amostras de solo os teores não trocáveis do calcário não dissolvido. A dissolução do calcário no solo, em um período de dois anos, deu-se dentro das expectativas com base no PRNT. Ao final dos cinco anos, mesmo a fração grosseira havia dissolvido quase que completamente. Os autores calcularam que as perdas anuais médias por lixiviação de $\mathrm{Ca}$ e $\mathrm{Mg}$ foram em termos de $\mathrm{CaCO}_{3}$ equivalentes a 200, 500, 900 e $1.200 \mathrm{~kg} \mathrm{ha}^{-1}$, respectivamente para aplicações de $0,3.000,6.000$ e $9.000 \mathrm{~kg}$ $\mathrm{ha}^{-1}$. A neutralização da acidez do solo abaixo da camada arável foi insignificante.

Espinoza \& Reis (1984) avaliaram a lixiviação de $\mathrm{Ca}, \mathrm{K}$ e $\mathrm{Mg}$, sob irrigação em um Latossolo Vermelho Escuro de cerrado, textura argilo-arenosa, pelo uso de cápsulas porosas durante o ciclo do desenvolvimento de milho. Para um total de $1.920 \mathrm{~mm}$ de água aplicada, a drenagem profunda (no plano de 105 $\mathrm{cm})$ variou entre 637 e $1.555 \mathrm{~mm}$. O movimento de lixiviação de nutrientes na profundidade $0-75 \mathrm{~cm}$ teve lugar nos primeiros 60 dias de irrigação. As concentrações de $\mathrm{Ca}, \mathrm{K}$ e $\mathrm{Mg}$, em geral, diminuíram de 38,8 e $12 \mathrm{mg} \mathrm{dm}^{-3}$ na profundidade de $0-30 \mathrm{~cm}$ para 5,1 e $2 \mathrm{mg} \mathrm{dm}^{-3}$, após 50 dias do início da irrigação. As perdas de $\mathrm{Ca}, \mathrm{K}$ e $\mathrm{Mg}$ na profundidade de $105 \mathrm{~cm}$ foram, em média, de 126,20 e $50 \mathrm{~kg} \mathrm{ha}^{-1}$, respectivamente.

Souza \& Ritchey (1986), em um experimento com a utilização de gesso agrícola, observaram que a redução no teor de sulfato na camada de 0 - 15 $\mathrm{cm}$ do solo foi diretamente proporcional à quantidade de água percolada. $\mathrm{Na}$ área onde os autores conduziram o experimento o $\mathrm{pH}$ foi corrigido para 5,5; nesse 
valor a retenção de sulfato é mínima ou quase nula. A movimentação média do sulfato após precipitação de $1.154 \mathrm{~mm}$ foi de $0,4 \mathrm{~mm} / \mathrm{mm}$ de água, reduzindo-se para $0,3 \mathrm{~mm} / \mathrm{mm}$ de água, quando o total de água acumulado foi de $2.276 \mathrm{~mm}$. A partir daí o enxofre movimentou-se muito pouco, reduzindo a sua intensidade. Citam ainda os autores que como a reação abaixo dos primeiros $20 \mathrm{~cm}$ é ácida, o sulfato provavelmente passa a ser retido pelo solo, o que reduz sua velocidade de movimentação.

\subsection{Efeito da adubação verde com tremoço sobre a produção de milho}

De acordo com Wutke (1993) o tremoço branco (Lupinus albus) é uma leguminosa anual ereta, herbácea, adaptada a uma faixa de temperatura entre 15 e $25^{\circ} \mathrm{C}$, fixa cerca de $130 \mathrm{~kg} \mathrm{ha}^{-1}$ ano $^{-1}$ de $\mathrm{N}$, produzindo 30.000 a $40.000 \mathrm{~kg}$ $\mathrm{ha}^{-1}$ de fitomassa verde e $5.000 \mathrm{~kg} \mathrm{ha}^{-1}$ de fitomassa seca. Em $1000 \mathrm{~kg}$ de fitomassa seca obtém-se $34 \mathrm{~kg}$ de N, 3,5 $\mathrm{kg}$ de $\mathrm{P}_{2} \mathrm{O}_{5}, 27 \mathrm{~kg}$ de $\mathrm{K}_{2} \mathrm{O}, 75 \mathrm{~kg}$ de $\mathrm{CaO}$ e $45 \mathrm{~kg}$ de $\mathrm{MgO}$. O tremoço pode ser utilizado em consórcio com videira, ou em rotação com o milho, antecedendo-o (para ser roçado no florescimento ou destinar-se à produção de sementes), propiciando aumentos de produtividade sem necessidade de adubação nitrogenada nesta cultura.

Corrêa $(1939)^{1}$, citado por Muzilli et al. (1983), há quase 60 anos atrás, no Rio Grande do Sul, já enfatizava a importância do tremoço para melhoramento e recuperação das terras, destacando a sua importância como adubo verde para melhoria das propriedades físicas e químicas do solo e seu valor como fonte de matéria orgânica e nitrogênio no desenvolvimento da lavoura. No Paraná, Muzilli et al. (1983), estudando alternativas para recuperação da capacidade produtiva de um Latossolo Roxo distrófico degradado, observaram que a massa seca

${ }^{1}$ CORREAA, O. Adubos verdes: o tremoço (Lupinus sp) e sua aplicação no melhoramento das terras. Porto Alegre: Secretaria de Estado dos Negócios da Agricultura, Indústria e Comércio, 1939. 50p. (Boletim, 26) 
incorporada de tremoço branco forneceu ao solo $3.311 \mathrm{~kg} \mathrm{ha}^{-1}$ de material orgânico que continha $111,6 \mathrm{~kg}$ de $\mathrm{N}, 11,2 \mathrm{~kg}$ de $\mathrm{P}_{2} \mathrm{O}_{5}, 89,7 \mathrm{~kg}$ de $\mathrm{K}_{2} \mathrm{O}, 24,2 \mathrm{~kg}$ de $\mathrm{CaO}$ e $13,9 \mathrm{~kg}$ de $\mathrm{MgO}$. Os autores consideraram que se apenas $75 \%$ do $\mathrm{N}$ fosse assimilável pelas plantas, a adubação verde teria fornecido ao milho $84 \mathrm{~kg}$ $\mathrm{ha}^{-1}$ de N. A utilização de adubação verde proporcionou um aumento médio de $26 \%$ na produtividade do milho em relação ao cultivo em solo degradado. Também no Paraná, em Latossolo Roxo distrófico, Derpsch (1984), avaliando a produção de matéria seca em espécies para adubação verde sem o uso de fertilizantes, verificou que o tremoço branco produziu $4.210 \mathrm{~kg} \mathrm{ha}^{-1}$ de matéria seca, tendo $90 \mathrm{~kg} \mathrm{ha}^{-1}$ de $\mathrm{N}$, cerca de $30 \mathrm{~kg}$ a mais que outras leguminosas avaliadas. $\mathrm{O}$ mesmo autor, avaliando o efeito residual de nove espécies para adubação verde sobre as culturas de milho, soja e feijão em plantio direto, verificou que o milho sem adubação nitrogenada mineral teve a maior produção após tremoço $\left(6.410 \mathrm{~kg} \mathrm{ha}^{-1}\right)$ e ervilhaca peluda $\left(6.320 \mathrm{~kg} \mathrm{ha}^{-1}\right)$. Em São Paulo, Kanthack et al. (1991), também em Latossolo Roxo distrófico, no qual se havia cultivado tremoço branco, comparando 4 doses de $\mathrm{N}\left(0,40,80\right.$ e $120 \mathrm{~kg} \mathrm{ha}^{-1}$ de N) observaram que não houve diferenças significativas nas produções de milho, nos teores de $\mathrm{N}$ nas folhas ou no teor de proteína nas sementes com aplicação das doses de nitrogênio.

Conforme se pôde observar pela revisão de literatura, os resultados das diversas pesquisas realizadas por várias vezes apresentaram-se discrepantes, tal fato se deve aos inúmeros fatores envolvidos no estudo do nitrogênio na planta $\mathrm{e}$ no solo, como a extração pelas plantas, a produtividade da cultura, o potencial de lixiviação (que depende dentre outros fatores, da textura do solo, da quantidade de água e da quantidade de $\mathrm{N}$ aplicado), a fonte do fertilizante aplicado, os cultivos anteriores além de outros fatores que tornam complexa a comparação dos resultados dos trabalhos estudados. 


\section{MATERIAL E MÉTODOS}

O experimento foi instalado em área da Escola Superior de Agricultura "Luiz de Queiroz", em Piracicaba (SP), utilizando-se milho como planta teste. As coordenadas geográficas da região são: $22^{\circ} 42^{\prime} 30^{\prime \prime} \mathrm{S}$ e $47^{\circ} 38^{\prime}$ 60 " W; a precipitação anual média é de $1.200 \mathrm{~mm}$, a temperatura anual média de $20^{\circ} \mathrm{C}$ e a altitude de $546 \mathrm{~m}$.

\subsection{Caracterização do solo da área experimental}

Para um estudo mais detalhado do solo da área utilizada, em setembro de 1996, foram abertas duas trincheiras, onde se fez a descrição dos perfis de solos e a coleta de amostras, por horizonte, para sua caracterização física e química. O solo foi classificado como Podzólico Vermelho Amarelo Latossólico distrófico, A moderado, textura média. A Tabela 1 contém os resultados das análises químicas realizadas nos horizontes dos perfis estudados.

\subsection{Balanço hídrico da região durante o experimento}

Em função da quantidade e distribuição das chuvas constituírem-se de fatores muito importantes na acidificação dos solos e lixiviação de nutrientes, foi elaborado o balanço hídrico do local durante o período do experimento, com dados fornecidos pelo Departamento de Física e Meteorologia da ESALQ. A Figura 1 ilustra a precipitação mensal no período de setembro/1996 a agosto/1997 e a Figura 2 ilustra o extrato do balanço hídrico decendial no mesmo período. 
Tabela 1. Análise química dos perfis estudados

\begin{tabular}{|c|c|c|c|c|c|c|c|c|c|c|c|c|c|c|}
\hline \multirow[t]{2}{*}{ HORIZ. } & \multirow{2}{*}{$\begin{array}{c}\text { PROF. } \\
\text { cm }\end{array}$} & \multirow{2}{*}{$\begin{array}{c}\text { pH } \\
\mathrm{CaCl}_{2}\end{array}$} & \multirow{2}{*}{$\begin{array}{c}\text { MO } \\
\mathrm{g} \mathrm{dm}^{-3}\end{array}$} & \multirow{2}{*}{\multicolumn{2}{|c|}{$\frac{P \quad \mathrm{~S}^{-\mathrm{SO}_{4}}}{\mathrm{mg} \mathrm{dm}^{-3}}$}} & \multirow{2}{*}{$\mathbf{K}$} & \multirow[t]{2}{*}{$\mathbf{C a}$} & Mg & \multicolumn{3}{|c|}{ Al $\mathbf{H}+$ Al SB $\mathbf{T}$} & \multicolumn{2}{|c|}{$\mathbf{V ~ m}$} & Argila \\
\hline & & & & & & & & \multicolumn{4}{|c|}{$\mathrm{mmol}_{\mathrm{c}} \mathrm{dm}^{-3}$} & \multicolumn{3}{|c|}{$\%$} \\
\hline AP1 & $0-14$ & 4,9 & 13 & 16 & 7 & 2,7 & 18 & 8 & 0 & 25 & 2954 & 54 & 0 & 18 \\
\hline AP2 & $14-32$ & 4,0 & 10 & 8 & 15 & 1,5 & 17 & 7 & 6 & 38 & 2664 & 41 & 19 & 22 \\
\hline BT1 & $32-58$ & 4,1 & 8 & 2 & 29 & 0,30 & 16 & 8 & 8 & 34 & 2458 & 41 & 25 & 27 \\
\hline BT2 & $58-100$ & 4,2 & 7 & 2 & 17 & 0,2 & 13 & 7 & 8 & 31 & 2051 & 39 & 29 & 22 \\
\hline & & & & & & $\mathrm{P}_{2}-$ & & & & & & & & \\
\hline AP1 & $0-8$ & 4,5 & 15 & 16 & 8 & 3,6 & 19 & 8 & 4 & 38 & 3169 & 45 & 11 & 20 \\
\hline AP2 & $8-27$ & 5,2 & 13 & 7 & 6 & 1,4 & 25 & 15 & 0 & 22 & 4163 & 65 & 0 & 22 \\
\hline BT1 & $27-50$ & 4,0 & 9 & 2 & 32 & 0,3 & 15 & 8 & 10 & 47 & 2370 & 33 & 30 & 28 \\
\hline BT2 & $50-73$ & 4,3 & 8 & 2 & 11 & 0,2 & 17 & 8 & 7 & 38 & 2563 & 40 & 22 & 27 \\
\hline BT3 & $73-160$ & 4,0 & 7 & 1 & 9,5 & 0,2 & 15 & 6 & 8 & 38 & 2159 & 36 & 28 & 26 \\
\hline
\end{tabular}

$\mathrm{P}_{1}$ : Perfil no início da área experimental

$\mathrm{P}_{2}$ : Perfil no centro da área experimental 


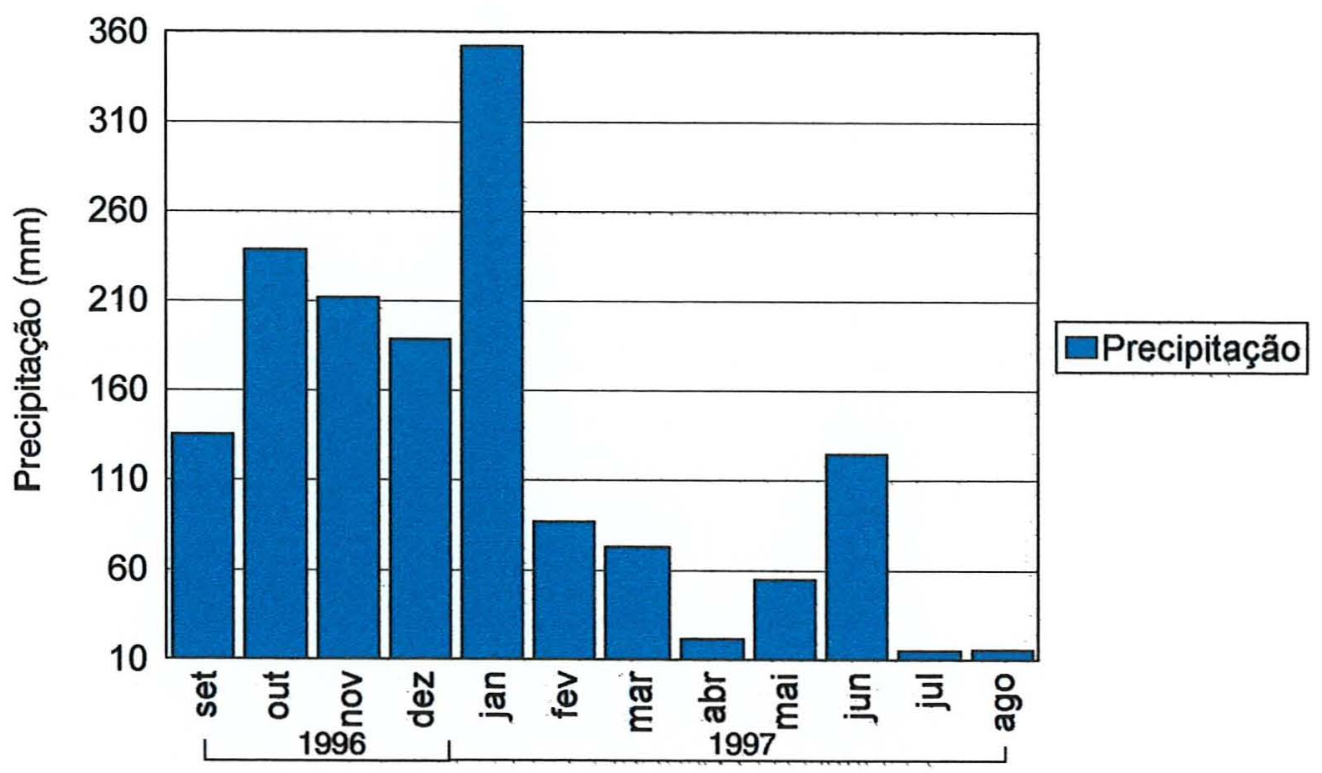

Figura 1 - Precipitação mensal no período de Set/96 a Ago/97

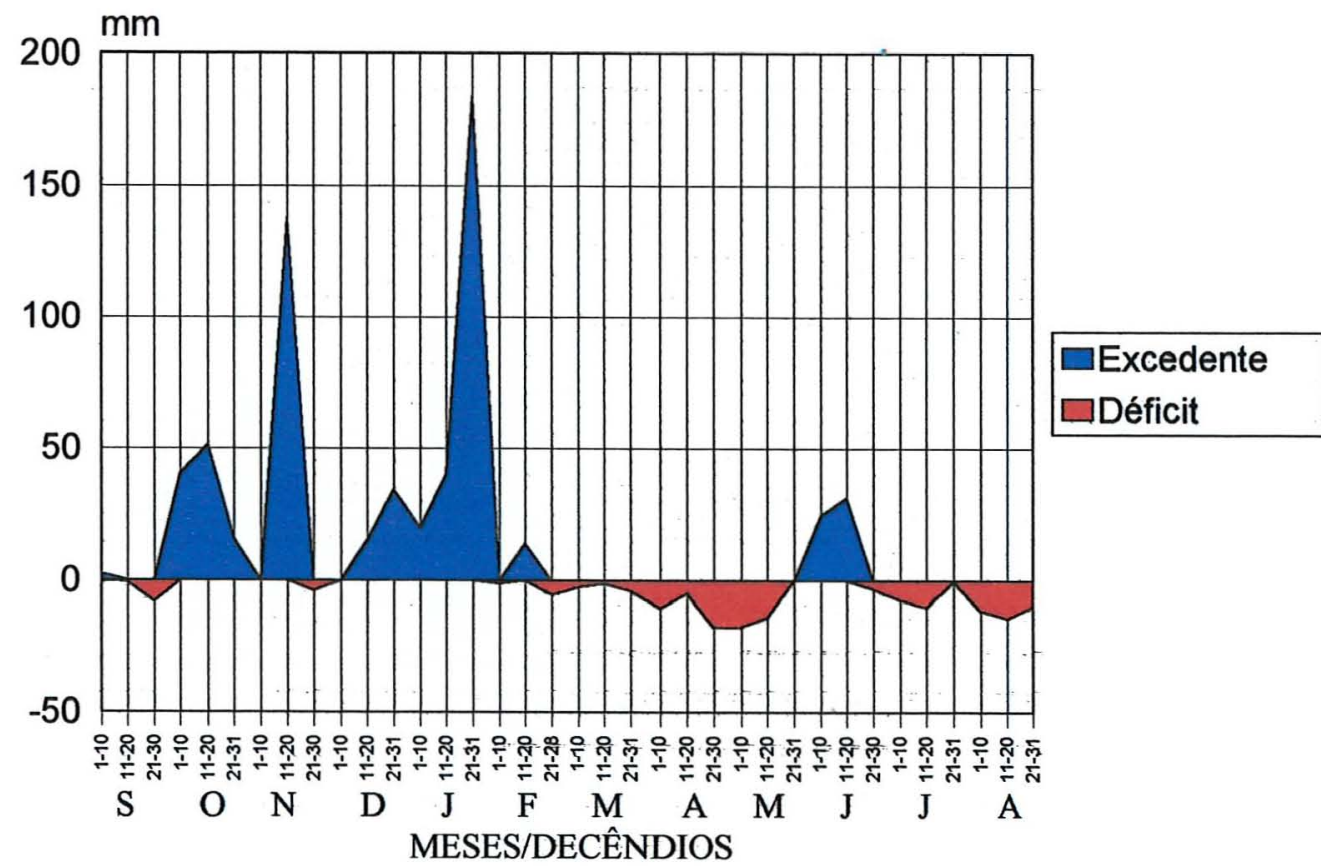

Figura 2 - Extrato do balanço hídrico decendial no período de Set/96 a Ago/97 


\subsection{Avaliação da produtividade de grãos e de matéria seca total do milho}

Para avaliação da produção de grãos de milho e da matéria seca total da parte aérea procedeu-se à pesagem, separadamente, de grãos e matéria seca. $\mathrm{O}$ delineamento experimental adotado foi o de blocos aleatorizados, com 3 tratamentos e 5 repetições. Os tratamentos utilizados foram os seguintes:

- SNM = Sem cobertura nitrogenada/com milho

- NAM = Cobertura com nitrato de amônio/com milho

- SAM = Cobertura com sulfato de amônio/com milho

\subsection{Amostragem do solo e avaliação dos atributos químicos}

Para avaliação dos atributos químicos do solo foram realizadas amostragens nas profundidades de 0-20, 20-40, 40-60, 60-80 e 80-100 cm, antes e após o cultivo do milho ( $1^{\mathrm{a}}$ época de amostragem e $2^{\mathrm{a}}$ época de amostragem); os atributos químicos avaliados foram: $\mathrm{pH}$, teor de matéria orgânica, cálcio, magnésio, enxofre, fósforo, potássio, alumínio, soma de bases, capacidade de troca catiônica, saturação por bases e saturação por alumínio. Em cada parcela foram coletadas com trado holandês 10 subamostras, na entrelinha, para cada profundidade, as quais foram homogeneizadas para constituir uma amostra composta nas profundidades indicadas anteriormente.

Cada parcela experimental possuía dimensões de $5,0 \mathrm{~m} \mathrm{x} \mathrm{7,5} \mathrm{m,}$ perfazendo $37,5 \mathrm{~m}^{2}$ de área total e $15 \mathrm{~m}^{2}$ de área útil.

Adotou-se o delineamento experimental de blocos aleatorizados com 5 repetições, em esquema fatorial $2 \times 5 \times 6$, possuindo 2 épocas de amostragem, 5 profundidades de amostragem e 6 tratamentos.

Os tratamentos adotados são formados pela combinação dos fatores: adubação nitrogenada de cobertura com sulfato de amônio ou nitrato de amônio e 
a cultura do milho, onde cada fator estava presente nos níveis 0 e 1 (ausência e presença). Os tratamentos utilizados foram:

- SNM = Sem cobertura nitrogenada/com milho

- SN $=$ Sem cobertura nitrogenada/sem milho

- NAM = Cobertura com nitrato de amônio/com milho

- NA = Cobertura com nitrato de amônio/sem milho

- SAM = Cobertura com sulfato de amônio/com milho

- SA = Cobertura com sulfato de amônio/sem milho

As amostras de solo da primeira e segunda amostragens foram secas ao ar e passadas em peneiras de $2 \mathrm{~mm}$ de abertura de malha, sendo submetidas às seguintes determinações, segundo descrito em Raij et al. (1987):

- $\mathrm{pH}$ em $\mathrm{CaCl}_{2}$ : leitura potenciométrica do $\mathrm{pH}$ da suspensão da terra em solução de $\mathrm{CaCl}_{2}$ 0,01 M, na relação $1: 2,5$;

- Acidez potencial $(\mathrm{H}+\mathrm{Al})$ : leitura potenciométrica do $\mathrm{pH}$ da suspensão da terra em solução tampão SMP, pH 7,5;

- Fósforo: extração com resina e determinação colorimétrica pelo método do molibdato de amônio;

- Cálcio, Magnésio e Potássio: extração com resina e determinação de $\mathrm{Ca}$ e $\mathrm{Mg}$ em espectrofotômetro de absorção atômica e de $\mathrm{K}$ em fotômetro de chama;

- Matéria Orgânica: oxidação da matéria orgânica do solo por dicromato de sódio na presença de ácido sulfúrico e determinação por fotocolorimetria;

- Alumínio: extração com $\mathrm{KCl} 1 \mathrm{~N}$ e determinação através de titulação com $\mathrm{NaOH} 0,025 \mathrm{~N}$;

- Enxofre (Sulfato): extração por acetato de amônio na presença de ácido acético e determinação fotocolorimétrica, através da turbidez formada pela precipitação do sulfato pelo cloreto de bário (Vitti, 1989). 


\subsection{Avaliação do tremoço (Lupinus albus) presente na área experimental e} preparo do solo

A área utilizada estava sendo explorada com ftremoço branco. Através de uma avaliação visual notou-se que as plantas desenvolviam-se desuniformemente. Em função disso foram provisoriamente demarcadas as 30 parcelas do experimento, a fim de se avaliar o tremoço e verificar se os blocos ficariam em áreas homogêneas. Para avaliação do tremoço criou-se uma escala de notas (1-Fraco, 2-Regular e 3-Bom), tendo como critério a cobertura do solo e o porte da planta, ao final da avaliação classificou-se o tremoço de 14 parcelas $(46,7 \%)$ como fraco, 15 como regular (50\%) e 1 como bom (3,3\%). Feito isso, realizou-se os ajustes necessários para a alocação de cada bloco em área mais homogênea possível. Como o tremoço destinava-se à produção de sementes, realizou-se a colheita, sendo os restos culturais incorporados por ocasião do preparo do solo (novembro/1996). Este por sua vez constou de aração profunda $(40 \mathrm{~cm})$, objetivando-se a eliminação da compactação do solo, e gradagem, para proceder-se ao acabamento e nivelamento da área para semeadura do milho.

\subsection{Instalação e condução do experimento}

Inicialmente foi programada a utilização de tratamentos compostos pela combinação de calcário, sulfato de amônio e a cultura do milho. Entretanto, análises preliminares do solo demonstraram que a saturação por bases encontravase com valores aproximados de $51 \%$, nas camadas superficiais, e portanto suficiente para o desenvolvimento normal das plantas. Substituiu-se a calagem por mais um adubo nitrogenado como tratamento, ou seja, adotou-se dois adubos nitrogenados na adubação de cobertura, sulfato de amônio (índice de acidez 110) e nitrato de amônio (índice de acidez 62). 
Em 03/12/96 foi realizado a semeadura do milho, o qual destinavase à produção de silagem. A adubação de plantio constou de $400 \mathrm{~kg} \mathrm{ha}^{-1} \mathrm{da}$ fórmula 4-30-16 +0,5\% de zinco, ao qual se adicionou $32 \mathrm{~kg} \mathrm{ha}^{-1}$ de uréia resultando em uma adubação de $30,56 \mathrm{~kg} \mathrm{ha}^{-1} \mathrm{de} \mathrm{N}, 111,6 \mathrm{~kg} \mathrm{ha}^{-1}$ de $\mathrm{P}_{2} \mathrm{O}_{5}, 50 \mathrm{~kg}$ $\mathrm{ha}^{-1}$ de $\mathrm{K}_{2} \mathrm{O}$ e $16,88 \mathrm{~kg} \mathrm{ha}^{-1}$ de $\mathrm{S}$. Para a realização dos cálculos foram utilizados os teores encontrados na análise química da fórmula 4-30-16, ou seja, 4,04\% de $\mathrm{N}, 27,9 \%$ de $\mathrm{P}_{2} \mathrm{O}_{5}, 12,5 \%$ de $\mathrm{K}_{2} \mathrm{O}$ e $4,22 \%$ de $\mathrm{S}$.

Foi utilizado o milho híbrido AG - 1051 (ciclo normal), sendo que a germinação ocorreu por volta do dia 09/12/96. Uma semana após a germinação do milho foram demarcadas definitivamente as parcelas, eliminando-se as plantas das parcelas sem cultura.

Nesta época também foi realizada a primeira amostragem do solo, como descrito anteriormente.

A adubação de cobertura constou de $100 \mathrm{~kg} \mathrm{ha}^{-1}$ de $\mathrm{N} \mathrm{e} 100 \mathrm{~kg} \mathrm{ha}^{-1}$ de $\mathrm{K}_{2} \mathrm{O}$, divididas em duas vezes, quando as plantas possuíam 4 pares de folhas (26/12/96) e 8 pares de folhas (11/01/97). Nas épocas de aplicação desses tratamentos os adubos foram pesados para cada parcela individualmente. A Tabela 2 contém a quantidade de fertilizantes aplicados por parcela em cada cobertura.

Tabela 2. Quantidade de fertilizantes aplicados por parcela em cada cobertura.

\section{Fertilizantes (g/parcela)}

\begin{tabular}{lccc} 
Tratamentos & Nitrato de amônio & Sulfato de amônio & Cloreto de potássio \\
\hline SNM & 0 & 0 & 312 \\
NAM & 568 & 0 & 312 \\
SAM & 0 & 937,5 & 312 \\
\hline
\end{tabular}


Aproximadamente 3 semanas após a emergência, ocorreu um ataque pouco severo de lagarta do cartucho, que foi controlado por ação das chuvas intensas que ocorreram nesse período. Por volta de 40 dias após a emergência, foi realizado o controle das ervas daninhas com Paraquat, na dosagem de $200 \mathrm{~g} \mathrm{l}^{-1}$, o qual foi aplicado de modo a não causar danos à cultura.

No período de 26 a 27/03/97, época de máxima acumulação de matéria seca, foi realizada a colheita do milho. Demarcou-se no centro de cada parcela uma área de $10,8 \mathrm{~m}^{2}$ ( 3 linhas centrais $\mathrm{x} 4 \mathrm{~m}$ de comprimento), onde foram colhidas as plantas inteiras, cortando-se rente ao solo. A matéria fresca total da área amostrada foi pesada, coletando-se amostras para determinação da umidade, que foram imediatamente pesadas, postas para secar em estufa de circulação forçada de ar a $65^{\circ} \mathrm{C}$ e novamente pesadas. Após as pesagens as espigas foram separadas e postas para secar ao sol. Estas foram debulhadas para obtenção dos grãos. Imediatamente coletaram-se amostras de cada tratamento para determinação da umidade do grão e correção da produção para umidade de $13 \%$.

A segunda amostragem do solo deveria ter sido realizada logo após a colheita da cultura, entretanto, a área apresentou-se extremamente resistente à penetração do trado, somente sendo possível a coleta após a ocorrência de chuvas na região, o que se deu no mês de junho. 


\section{RESULTADOS E DISCUSSÃO}

\subsection{Produtividade de grãos e de matéria seca total da parte aérea do milho}

Os resultados referentes à produtividade de grãos e de matéria seca do milho após serem convertidos em $\mathrm{kg} \mathrm{ha}^{-1}$, foram analisados estatisticamente, sendo estudadas as variáveis produtividade de grãos, produtividade de matéria seca total e eficiência de transformação de matéria seca em grãos (esta última variável é resultante da razão percentual entre produção de grãos e produção de matéria seca total).

A análise evidenciou que ocorreram diferenças significativas entre os tratamentos para as variáveis produtividade de grãos e produtividade de matéria seca total; entretanto, para a variável eficiência de transformação de matéria seca em grãos não foram evidenciadas diferenças significativas entre os tratamentos.

Em virtude do grau de liberdade do resíduo ter sido inferior a 10, o que é considerado mínimo do ponto de vista prático para realização da análise de variância, foi verificada a validade do delineamento para o tamanho de amostra, que comprovou ser possível a realização desta análise com respeito à estimação da variância residual e efeitos principais. Para isso foi utilizado o sistema SAS no módulo LAB.

Para a variável eficiência de transformação da matéria seca total em grãos, foi evidenciado que esta não diferiu estatisticamente, em função dos 
tratamentos utilizados, provavelmente por ser uma característica inerente do híbrido utilizado que não sofre influência de fatores ambientais como a fertilidade do solo, que, como será visto posteriormente, influenciou tanto a produção de grãos como a de matéria seca total. Na Tabela 3 é apresentado o resultado do teste de comparação de médias pelo teste t-Student para as variáveis estudadas.

Tabela 3. Médias da produtividade de grãos, matéria seca total e eficiência obtidas em cada tratamento

\begin{tabular}{lcrc}
\hline \multicolumn{1}{c}{ Tratamentos } & Grãos & Matéria seca & Eficiência* \\
\hline \multirow{2}{*}{ Sem cobertura nitrogenada } & \multicolumn{3}{c}{$\left(\mathbf{k g ~ h a}^{-1}\right)$} \\
Nitrato de amônio & $4568 \mathrm{~b}$ & $9259 \mathrm{~b}$ & $\mathbf{( \% )}$ \\
Sulfato de amônio & $6348 \mathrm{a}$ & $12937 \mathrm{a}$ & $49,9 \mathrm{a}$ \\
& $6135 \mathrm{a}$ & $12856 \mathrm{a}$ & $47,8 \mathrm{a}$ \\
\hline
\end{tabular}

Médias seguidas de mesma letra minúscula na coluna não diferem pelo teste t-Student ao nível de 0,05 ${ }^{*}$ Eficiência $=(\mathrm{kg}$ grão/ $\mathrm{kg}$ matéria seca total $) \times 100$

A Figura 3 ilustra os resultados obtidos no teste de comparação de médias para a variável produtividade de grãos.

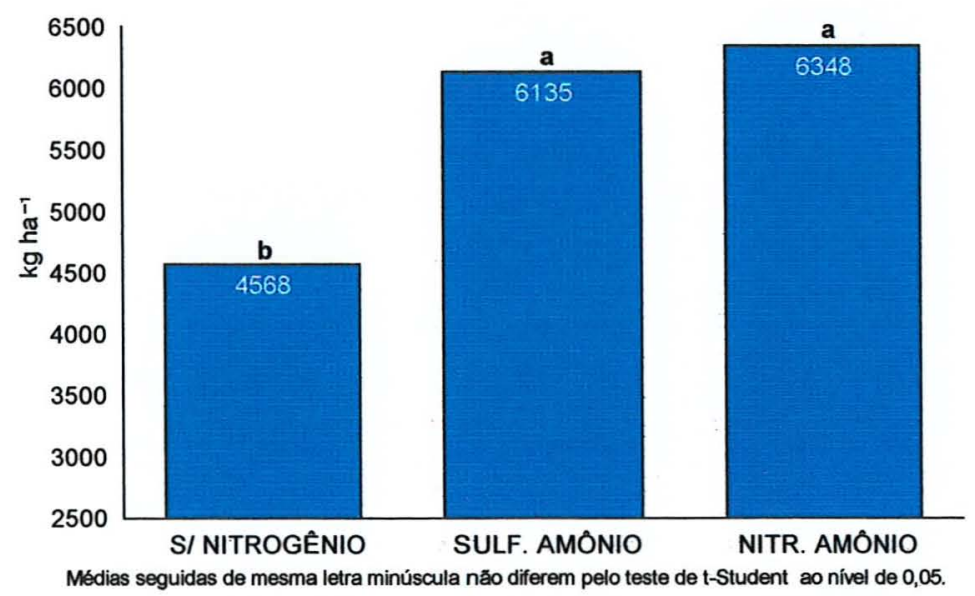

Figura 3 - Produtividade média de grãos em cada tratamento. 
A Figura 4 ilustra os resultados obtidos no teste de comparação de médias para a variável produtividade de matéria seca total da parte aérea do milho.

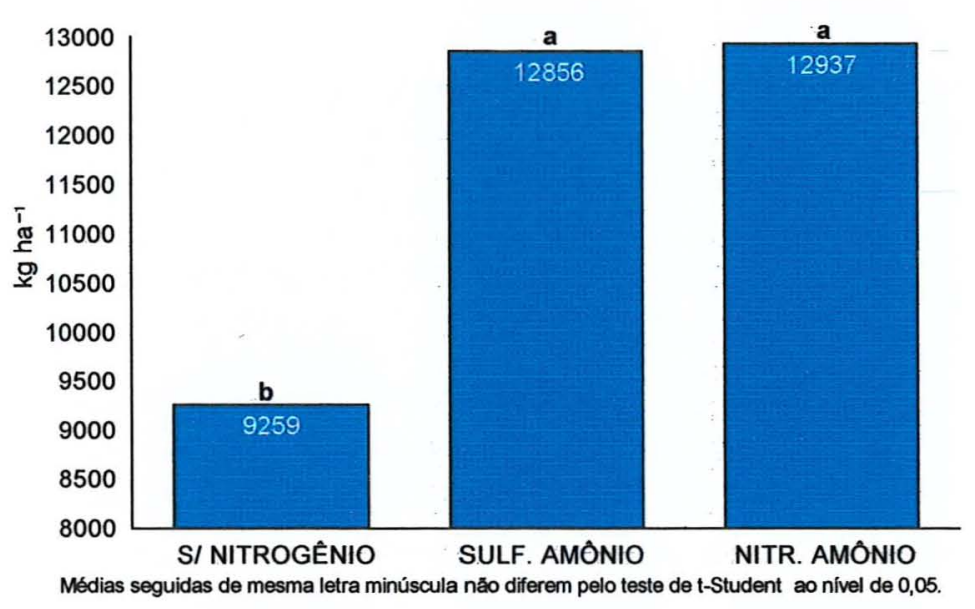

Figura 4 - Produtividade média de matéria seca total em cada tratamento.

Os resultados apresentados evidenciam que, tanto para a produtividade de grãos quanto para a de matéria seca total, os valores não diferiram entre as fontes nitrogenadas (nitrato e sulfato de amônio); entretanto, esses tratamentos diferiram do tratamento sem adubação nitrogenada mineral. Esses resultados são discordantes dos encontrados por Muzilli et al. (1983), Derpsch (1984) e Kanthack et al. (1991), onde tratamentos utilizando tremoço como adubo verde tiveram produções iguais ou superiores aos tratamentos com $\mathrm{N}$ mineral. Entretanto, todos esses experimentos foram instalados em Latossolo Roxo distrófico, que provavelmente possui um menor potencial de resposta à adubação nitrogenada do que o Podzólico Vermelho Amarelo Latossólico distrófico, onde o presente trabalho foi conduzido. $\mathrm{O}$ menor potencial de resposta à adubação nitrogenada do Latossolo Roxo pode ser devido, principalmente, ao maior teor de matéria orgânica presente nos horizontes superficiais deste solo em relação aos menores teores encontrados no Podzólico Vermelho Amarelo Latossólico distrófico. O solo utilizado no trabalho de Kanthack et al. (1991) 
apresentava um teor de matéria orgânica de $31 \mathrm{~g} \mathrm{dm}^{-3}$ nos horizontes superficiais, enquanto que o solo onde foi conduzido o experimento em questão apresenta um máximo de $15 \mathrm{~g} \mathrm{dm}^{-3}$.

\subsection{Modificação dos atributos químicos do solo em função dos tratamentos utilizados}

Os resultados das análises de solo foram submetidos à análise estatística, de modo a avaliar a variação dos atributos químicos do solo em função dos tratamentos. Foram comparadas as médias dos resultados da primeira época de amostragem com as da segunda época de amostragem, como também para cada fator dentro de cada época. Ressalte-se que a primeira amostragem é considerada uma condição inicial, igual para todos os tratamentos. Para a realização da análise estatística foi necessária a transformação da maioria dos dados, utilizando a transformação ótima de Box-Cox. Foram realizados testes para heterogeneidade da variância (Levenes) e análise de resíduo para "outliers". Foram estudadas as seguintes interações: Época $x$ Profundidade, Época $x$ Fertilizante e Época $x$ Cultura.

Os resultados demonstraram que as modificações significativas dos atributos do solo ocorreram para matéria orgânica, fósforo, enxofre e potássio em todas as interações. 


\subsubsection{Matéria orgânica}

A Tabela 4 contém os teores de matéria orgânica do solo obtidos nas interações estudadas.

Tabela 4. Teores de matéria orgânica do solo

\begin{tabular}{|c|c|c|c|}
\hline & \multirow{2}{*}{$\begin{array}{l}\text { FATORES } \\
\text { Profundidade }(\mathrm{cm})\end{array}$} & \multicolumn{2}{|c|}{ ÉPOCA } \\
\hline & & 1 & 2 \\
\hline & $0-20$ & $15,64 \mathrm{aA}$ & $9,87 \mathrm{aB}$ \\
\hline & $20-40$ & $14,86 \mathrm{aA}$ & $8,93 \mathrm{bB}$ \\
\hline & $40-60$ & $12,95 \mathrm{bA}$ & $6,79 \mathrm{cB}$ \\
\hline & $60-80$ & $12,52 \mathrm{bcA}$ & $6,58 \mathrm{cB}$ \\
\hline & $80-100$ & $11,79 \mathrm{cA}$ & $6,40 \mathrm{cB}$ \\
\hline \multirow[t]{7}{*}{ M.O. $\left(\mathrm{g} \mathrm{dm}^{-3}\right)$} & \multicolumn{3}{|l|}{ Fertilizante } \\
\hline & Nitrato de Amônio & $13,68 \mathrm{aA}$ & $7,64 \mathrm{aB}$ \\
\hline & Sulfato de Amônio & $13,42 \mathrm{aA}$ & $7,78 \mathrm{aB}$ \\
\hline & Sem Nitrogênio & $13,44 \mathrm{aA}$ & $7,54 \mathrm{aB}$ \\
\hline & \multicolumn{3}{|l|}{$\overline{\text { Cultura }}$} \\
\hline & $\overline{\text { Com }}$ & $13,65 \mathrm{aA}$ & $7,83 \mathrm{aB}$ \\
\hline & $\overline{\text { Sem }}$ & $13,37 \mathrm{aA}$ & $7,48 \mathrm{aB}$ \\
\hline
\end{tabular}

Médias seguidas de mesma letra minúscula (coluna) não diferem pelo teste t-Student ao nível de 0,05 Médias seguidas de mesma letra maiúscula (linha) não diferem pelo teste t-Student ao nível de 0,05

A Figura 5 ilustra o comportamento da matéria orgânica do solo nas profundidades estudadas entre as duas épocas de amostragem. 


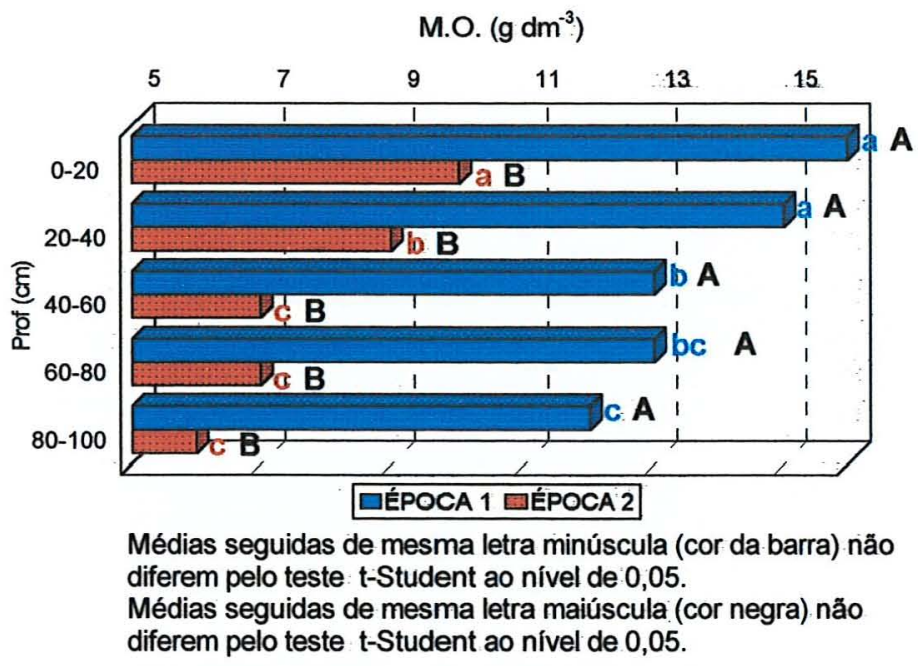

Figura 5 - Teores de matéria orgânica para a interação época x profundidade

Os resultados evidenciam que houve uma variação significativa nos teores de matéria orgânica para cada profundidade entre as épocas de amostragem, sendo os teores da primeira época sempre superiores aos da segunda época. Essa variação possivelmente seja devida à incorporação do tremoço existente na área por ocasião do preparo do solo (primeira amostragem). Como essa leguminosa possui uma relação $\mathrm{C} / \mathrm{N}$ em torno de $17 / 1$, proporcionando o equilíbrio entre a mineralização e a imobilização do $\mathrm{N}$, provavelmente a matéria orgânica entrou em decomposição resultando em teores menores na época da segunda amostragem (final do experimento). Os resultados estão de acordo com Sánchez (1981), que afirma que em áreas cultivadas ocorre constantemente a redução de matéria orgânica, pela remoção dos produtos das colheitas.

Também deve-se observar que os teores de matéria orgânica na $1^{\text {a }}$ amostragem parecem estar superestimados, pois os teores são superiores aos encontrados normalmente no solo utilizado; possivelmente a superestimativa deva-se a erros analíticos, já que os dados parecem apresentar uma variação constante. 
Nas interações Época x Fertilizante e Época x Cultura só foram evidenciadas variações significativas nos teores de matéria orgânica no solo em relação às épocas de amostragem, não ocorrendo influência dos fertilizantes e da ausência ou presença da cultura nesse teores.

\subsubsection{Fósforo}

$\mathrm{Na}$ Tabela 5 estão representados os teores de fósforo nas interações estudadas.

Tabela 5. Teores de fósforo no solo

\begin{tabular}{|c|c|c|c|}
\hline & FATORES & ÉP & \\
\hline & Profundidade (cm) & 1 & 2 \\
\hline & $0-20$ & $14,09 \mathrm{aA}$ & $8,27 \mathrm{aB}$ \\
\hline & $20-40$ & $10,14 \mathrm{bA}$ & $5,30 \mathrm{bB}$ \\
\hline & $40-60$ & $5,57 \mathrm{cA}$ & $2,98 \mathrm{cB}$ \\
\hline & $60-80$ & $4,00 \mathrm{dA}$ & $2,76 \mathrm{cB}$ \\
\hline & $80-100$ & $3,50 \mathrm{dA}$ & $2,75 \mathrm{cB}$ \\
\hline$P\left(\mathrm{mg} \mathrm{dm}^{-3}\right)$ & Fertilizantes & & \\
\hline & Nitrato de Amônio & $6,43 \mathrm{aA}$ & $3,91 \mathrm{aB}$ \\
\hline & Sulfato de Amônio & $6,25 \mathrm{aA}$ & $3,90 \mathrm{aB}$ \\
\hline & Sem Nitrogênio & 5,68 aA & $3,77 \mathrm{aB}$ \\
\hline & Cultura & & \\
\hline & Com & $6,14 \mathrm{aA}$ & $3,91 \mathrm{aB}$ \\
\hline & Sem & $6,25 \mathrm{aA}$ & $3,90 \mathrm{aB}$ \\
\hline
\end{tabular}

Médias seguidas de mesma letra minúscula (coluna) não diferem pelo teste t-Student ao nível de 0,05 Médias seguidas de mesma letra maiúscula (linha) não diferem pelo teste t-Student ao nível de 0,05 
$\mathrm{Na}$ Figura 6 são apresentados os teores de fósforo em cada profundidade nas duas épocas de plantio. Verifica-se que os teores de fósforo reduziram-se entre a primeira e segunda época. Também pode ser constatada uma redução nos teores do elemento ao longo do perfil, tanto para a primeira como para a segunda época de amostragem.

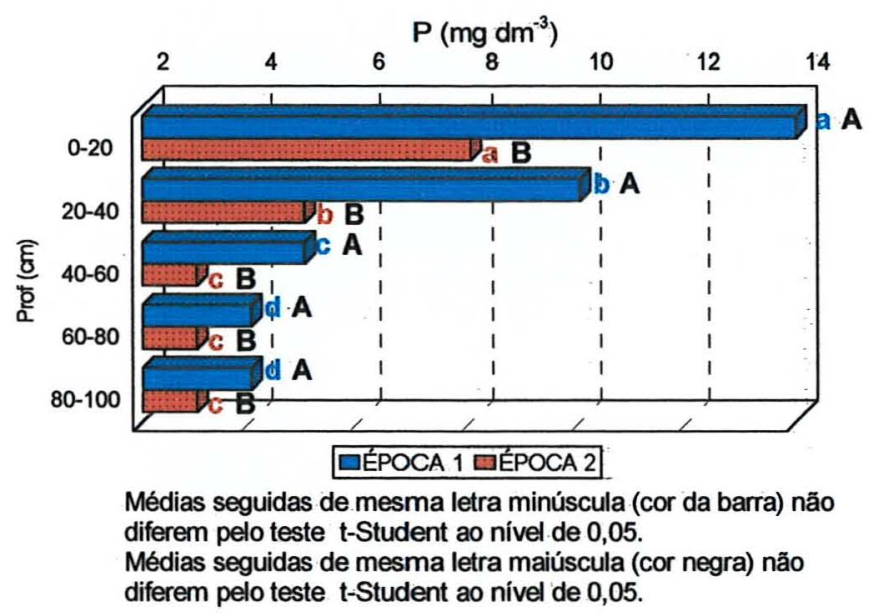

Figura 6 - Teores de fósforo para a interação época x profundidade

A Figura 7 ilustra a variação dos teores de fósforo em função dos fertilizantes nitrogenados utilizados em cada época de amostragem. Observa-se que os fertilizantes não influenciaram os teores de $\mathrm{P}$, entretanto, evidencia-se que houve uma redução significativa dos teores de fósforo entre as épocas de amostragem. Os mesmos resultados foram observados ao longo do perfil do solo.

A interpretação da interação Época $x$ Fertilizante também se aplica à interação Época x Cultura, concluindo-se que a presença ou a ausência do milho não influenciou os teores de fósforo. Para explicar esses resultados é necessária uma abordagem considerando-se a ocorrência de adsorção de fósforo pelo solo, que é responsável pela imobilização reversível ou não de grande fração do 
fósforo, como afirmam diversos autores (Brady, 1989; Raij, 1991 e Sánchez, 1981).

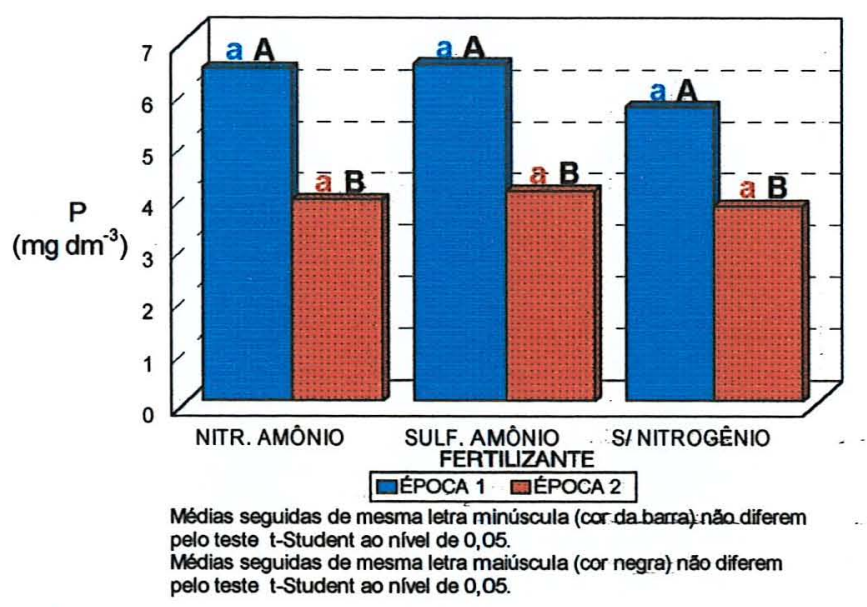

Figura 7 - Teores de fósforo para a interação época $\mathrm{x}$ fertilizante

No presente trabalho todas as parcelas experimentais receberam por ocasião do plantio do milho adubação fosfatada na dosagem de $111,6 \mathrm{~kg} \mathrm{ha}^{-1}$ de $\mathrm{P}_{2} \mathrm{O}_{5}$. Andrade et al. (1975), em trabalho desenvolvido na região, determinaram a extração média de $\mathrm{P}_{2} \mathrm{O}_{5}$ pela cultura do milho em torno de $64 \mathrm{~kg} \mathrm{ha}^{-1}$. Considerando-se os teores encontrados nas camadas superficiais da primeira amostragem como baixo, ou seja, a maioria do fósforo necessário para a planta foi fornecida pelo fertilizante, pode-se estimar que cerca de $47 \mathrm{~kg} \mathrm{ha}^{-1}$ do $\mathrm{P}_{2} \mathrm{O}_{5}$ aplicado possivelmente foi imobilizado por adsorção, tornando-se indisponível e não sendo detectado pela análise de solo de rotina.

\subsubsection{Enxofre}

Observa-se através da Tabela 6 que para a interação Época $\mathrm{x}$ Profundidade os teores de enxofre foram mais elevados nas camadas subsuperficiais do que nas superficiais nas duas épocas de amostragem, apresentando-se sempre semelhantes entre as profundidades de $40 \mathrm{~cm}$ e $100 \mathrm{~cm}$. 
Nas camadas superficiais, para a primeira época, os teores foram semelhantes entre as camadas de 0 a $20 \mathrm{~cm}$ e de 20 a $40 \mathrm{~cm}$, entretanto, para a segunda época esses teores diferiram entre essas camadas do solo, ocorrendo uma menor redução na camada de 20 a $40 \mathrm{~cm}$.

Tabela 6. Teores de enxofre no solo

\begin{tabular}{|c|c|c|c|}
\hline & \multirow{2}{*}{$\begin{array}{l}\text { FATORES } \\
\text { Profundidade (cm) }\end{array}$} & \multicolumn{2}{|c|}{ ÉPOCA } \\
\hline & & 1 & 2 \\
\hline & $0-20$ & $22,02 \mathrm{bA}$ & $11,13 \mathrm{cB}$ \\
\hline & $20-40$ & $23,43 \mathrm{bA}$ & $15,57 \mathrm{bB}$ \\
\hline & $40-60$ & $31,84 \mathrm{aA}$ & $30,52 \mathrm{aA}$ \\
\hline & $60-80$ & $34,19 \mathrm{aA}$ & $35,99 \mathrm{aA}$ \\
\hline \multirow[t]{8}{*}{$\mathrm{S}-\mathrm{SO}_{4}{ }^{2-} \quad\left(\mathrm{mg} \mathrm{dm}^{-3}\right)$} & $80-100$ & $37,54 \mathrm{aA}$ & 36,37 aA \\
\hline & Fertilizante & & \\
\hline & Nitrato de Amônio & $29,46 \mathrm{aA}$ & $19,35 \mathrm{bB}$ \\
\hline & Sulfato de Amônio & $27,90 \mathrm{aA}$ & $27,60 \mathrm{aA}$ \\
\hline & Sem Nitrogênio & 29,57 aA & $21,60 \mathrm{bB}$ \\
\hline & Cultura & & \\
\hline & Com & 29,82 aA & $22,28 \mathrm{aB}$ \\
\hline & Sem & 28,15 aA & $22,77 \mathrm{aB}$ \\
\hline
\end{tabular}

Médias seguidas de mesma letra minúscula (coluna) não diferem pelo teste t-Student ao nível de 0,05 Médias seguidas de mesma letra maiúscula (linha) não diferem pelo teste t-Student ao nível de 0,05

Através da observação dos dados de precipitação e do balanço hídrico (Figuras 1 e 2) verifica-se que houve um grande excedente hídrico nos meses de dezembro de 1996 e principalmente janeiro de 1997. A partir de fevereiro de 1997, praticamente não houve mais excedente hídrico, o que sugere um caminhamento de íons como o sulfato apenas para o mês de janeiro de 1997. 
Pode-se comentar também que, de forma atípica, não houve excedente hídrico nos meses de fevereiro e março, o que contribuiria para maiores perdas de elementos no perfil do solo.

O excedente hídrico nos meses de dezembro/96 e janeiro/97 deve ter influenciado sobremaneira a lixiviação do ânion sulfato, o que está de acordo com os resultados experimentais obtidos por Souza \& Ritchey (1986). Conforme pode ser observado na Figura 8, onde estão representados, no perfil, os teores de sulfato e o pH nas duas épocas de amostragem, ocorreu a movimentação do sulfato das camadas superficiais para as subsuperficiais com o décrescimo do $\mathrm{pH}$, o que também foi constatado por Couto (1979).

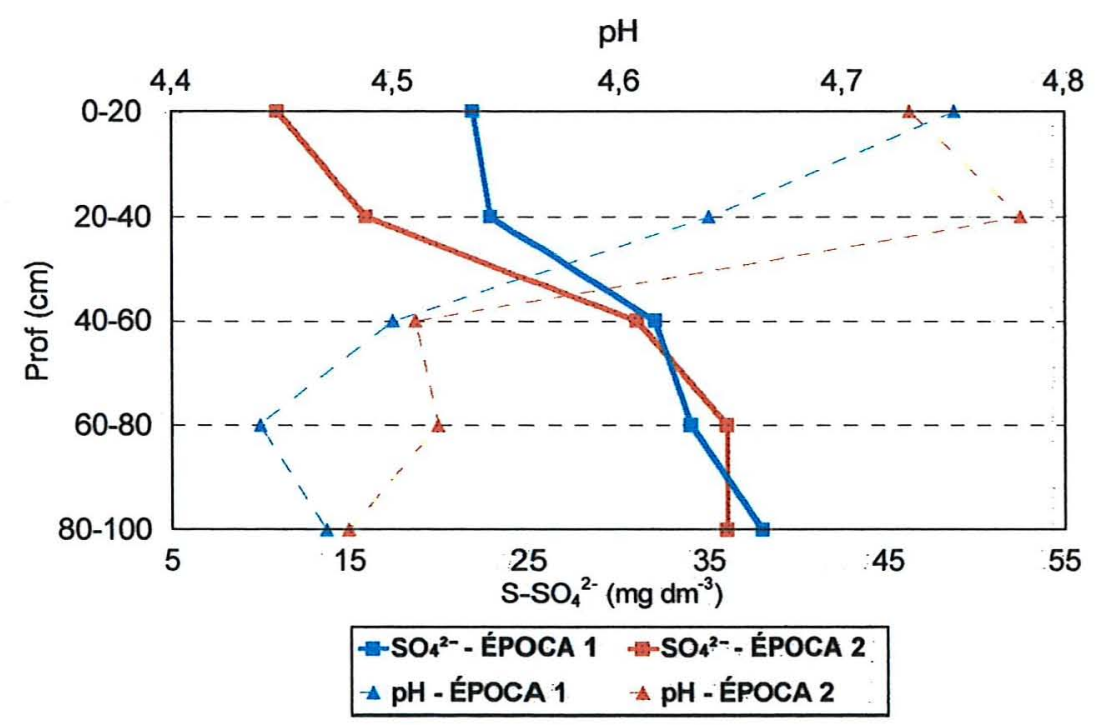

Figura 8 - Teor de sulfato e $\mathrm{pH}$ no perfil do solo

A Figura 9 representa os teores de sulfato para a interação Época $\mathrm{x}$ Fertilizante. Observa-se que na segunda época de amostragem evidencia-se que o tratamento com sulfato de amônio apresentou teores superiores aos demais, observando-se ainda a manutenção do enxofre entre as épocas de amostragem. Os demais tratamentos não diferiram entre si e apresentam uma forte redução no teor 
de enxofre entre as duas épocas de amostragem. Ressalte-se que o comportamento observado é válido para todas as camadas do perfil do solo.

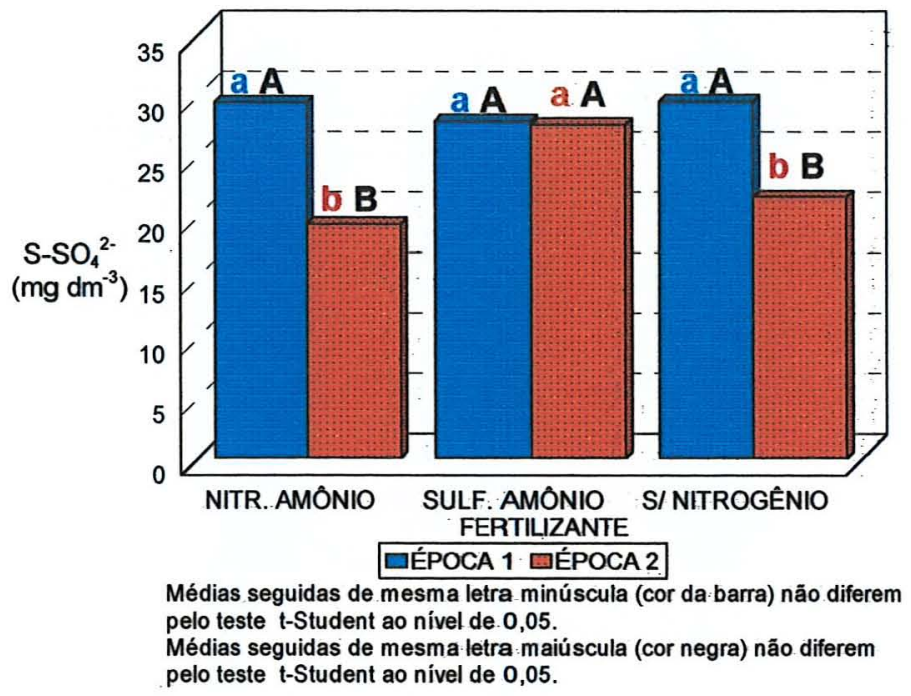

Figura 9 - Teores de sulfato em cada tratamento

Todos os tratamentos receberam no plantio $16,88 \mathrm{~kg} \mathrm{ha}^{-1}$ de $\mathrm{S}$, e os tratamentos com sulfato de amônio receberam através desse adubo mais $120 \mathrm{~kg}$ $\mathrm{ha}^{-1}$ de S por ocasião da cobertura nitrogenada, perfazendo um total de $136,88 \mathrm{~kg}$ $\mathrm{ha}^{-1}$ de S. Andrade et al. (1975) calcularam a extração do enxofre pela cultura do milho em cerca de $16 \mathrm{~kg} \mathrm{ha}^{-1}$. Considerando-se que na época do plantio o enxofre no solo se encontrava em níveis adequados, estima-se que para os tratamentos com nitrato de amônio e sem adubação nitrogenada em cobertura somente o enxofre natural do solo seria lixiviado, enquanto que nos tratamentos com sulfato de amônio cerca de $120 \mathrm{~kg} \mathrm{ha}^{-1}$ de S poderiam ser lixiviados pela intensa precipitação ocorrida no início do desenvolvimento do milho. Essas hipóteses podem ser visualizadas na Figura 10. 


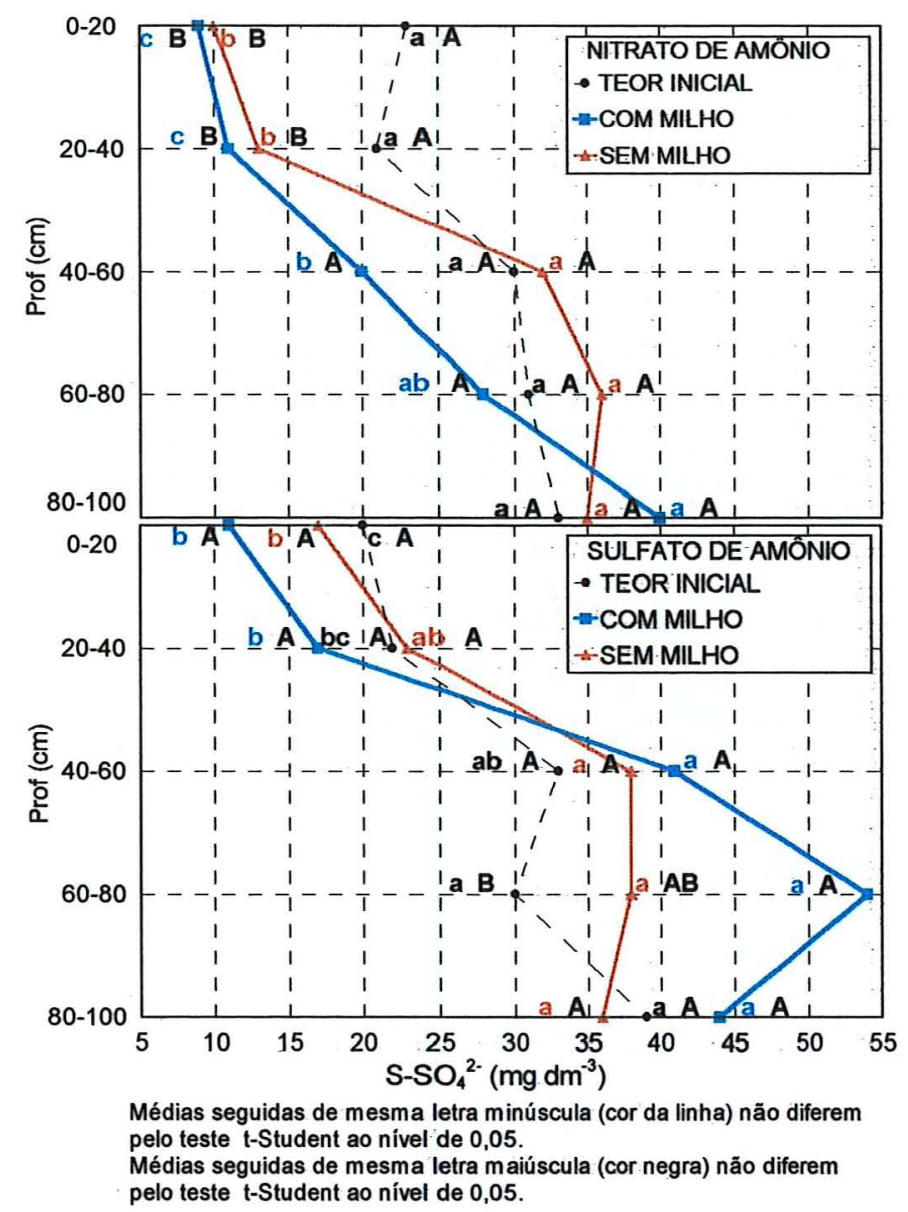

Figura 10 - Teores de sulfato ao longo do perfil nos tratamentos com sulfato de amônio e nitrato de amônio

Conforme pode ser observado, para os tratamentos com sulfato de amônio a lixiviação de sulfato foi consideravelmente maior que nos tratamentos com nitrato. Já para a extração pela cultura, evidencia-se que há uma redução não significativa entre os tratamentos com e sem milho; entretanto, no tratamento com sulfato de amônio, por ser a extração insignificante frente à lixiviação, não houve diferenças nos teores de enxofre nas parcelas com e sem cultura. É importante enfatizar, o que já foi comentado anteriormente, que devido ao excedente hídrico ocorrido entre dezembro/96 e janeiro/97 grande parte do enxofre deve ter sido lixiviado neste período, reduzindo-se os teores nas camadas superficiais e ficando 
fora do alcance das raízes. Por outro lado, o déficit hídrico ocorrido a partir de fevereiro/97 deve ter provocado uma menor extração de nutrientes pela cultura, implicando no comprometimento da produção do milho.

\subsubsection{Potássio}

A Tabela 7 contém os teores de potássio no solo nas interações estudadas.

Tabela 7. Teores de potássio no solo

\begin{tabular}{|c|c|c|c|}
\hline & FATORES & & $\overline{\mathbf{C A}}$ \\
\hline & Profundidade $(\mathrm{cm})$ & 1 & 2 \\
\hline & $0-20$ & $1,18 \mathrm{aB}$ & $2,11 \mathrm{aA}$ \\
\hline & $20-40$ & $1,24 \mathrm{aA}$ & $1,27 \mathrm{bA}$ \\
\hline & $40-60$ & $0,89 \mathrm{bA}$ & $0,95 \mathrm{cA}$ \\
\hline & $60-80$ & $0,58 \mathrm{cA}$ & $0,67 \mathrm{dA}$ \\
\hline & $80-100$ & $0,40 \mathrm{~dB}$ & $0,53 \mathrm{eA}$ \\
\hline $\mathrm{K}\left(\mathrm{mmol}_{\mathrm{c}} \mathbf{d m}^{-3}\right)$ & Fertilizante & & \\
\hline & Nitrato de Amônio & $0,90 \mathrm{aB}$ & $1,15 \mathrm{aA}$ \\
\hline & Sulfato de Amônio & $0,77 \mathrm{aB}$ & $1,04 \mathrm{abA}$ \\
\hline & Sem Nitrogênio & $0,80 \mathrm{aA}$ & $0,93 \mathrm{bA}$ \\
\hline & Cultura & & \\
\hline & Com & $0,79 \mathrm{aA}$ & $0,99 \mathrm{aB}$ \\
\hline & $\overline{\text { Sem }}$ & $0,85 \mathrm{aA}$ & $1,09 \mathrm{aB}$ \\
\hline
\end{tabular}

Médias seguidas de mesma letra minúscula (coluna) não diferem pelo teste t-Student ao nível de 0,05 Médias seguidas de mesma letra maiúscula (linha) não diferem pelo teste t-Student ao nível de 0,05

A Figura 11 ilustra os teores de potássio na interação Época $\mathrm{X}$ Profundidade. Comparando-se as duas épocas de amostragem observa-se que os 
teores na segunda época nas camadas de 0 a $20 \mathrm{~cm}$ e de 80 a $100 \mathrm{~cm}$, foram superiores aos da primeira época; na camada compreendida entre 20 e $80 \mathrm{~cm}$ não houve variação entre os teores. Quando se compara a variação entre os teores em relação à profundidade dentro de cada época, evidencia-se que houve variação significativa entre todas as camadas nas duas épocas estudadas, diminuindo o teor de potássio com a profundidade, com exceção das camadas de 0 a $20 \mathrm{~cm}$ e 20 a $40 \mathrm{~cm}$ na primeira época que, não diferiram significativamente. Esses resultados estão de acordo com o comportamento de potássio normalmente encontrado em solos tropicais.

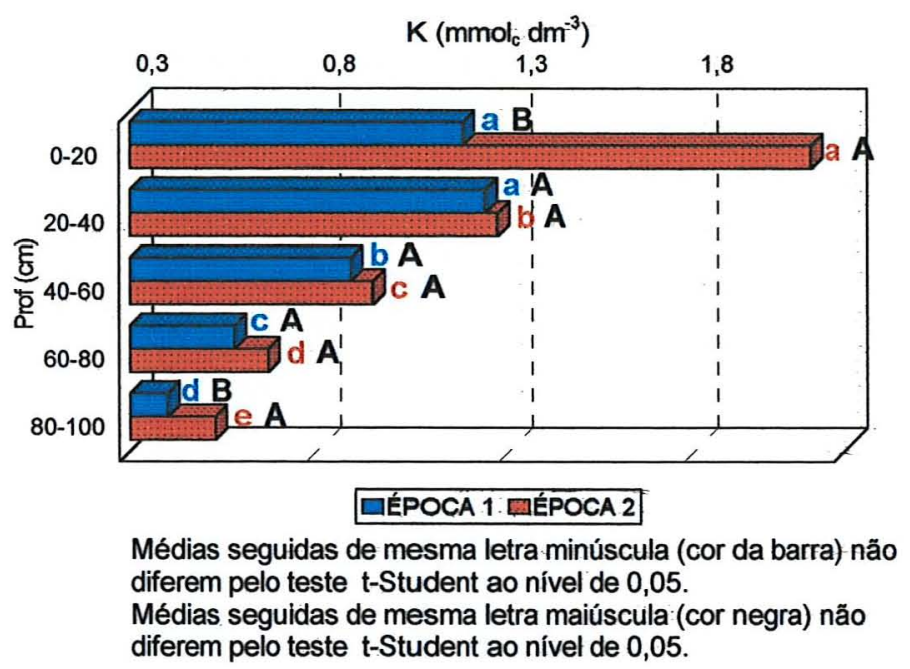

Figura 11 - Potássio na interação época x profundidade

A Figura 12 representa os teores de potássio na interação Época $\mathrm{x}$ Fertilizante. Observa-se que na segunda época os teores nos tratamentos com nitrato de amônio e sulfato de amônio foram superiores aos da primeira época. $\mathrm{Na}$ comparação entre os fertilizantes para a segunda época, os teores de potássio foram semelhantes nos tratamentos com sulfato de amônio, nitrato de amônio e 
sem nitrogênio mineral em cobertura, apresentando os dois últimos diferenças significativas quanto ao teor de potássio.

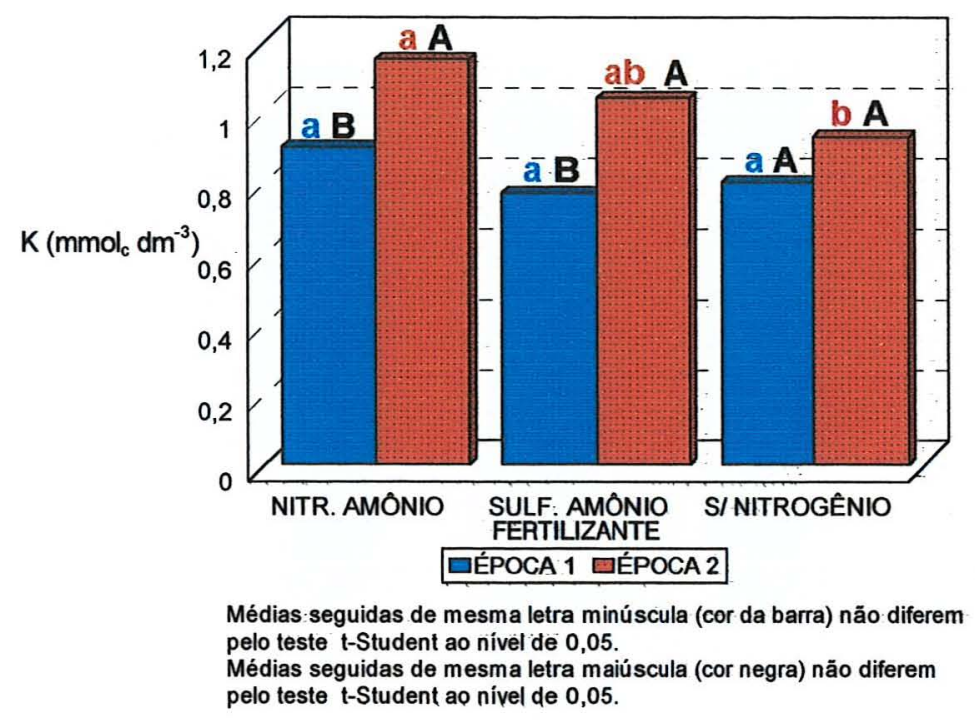

Figura 12 - Potássio na interação época x fertilizante

A Figura 13 ilustra os teores de potássio para a interação Época $\mathrm{x}$ Cultura. Na comparação entre as épocas, ambos os tratamentos evidenciaram diferenças significativas, sendo os teores da segunda época de amostragem superiores aos da primeira. A elevação dos teores na segunda época, ou seja, após a aplicação dos tratamentos, que evidencia-se em todas as interações estudadas, pode ser explicada pela adubação potássica que foi fornecida a todas as parcelas por ocasião do plantio e da cobertura, perfazendo um total de $150 \mathrm{~kg} \mathrm{ha}^{-1}$ de $\mathrm{K}_{2} \mathrm{O}$. Os teores de potássio na camada de 0 a $20 \mathrm{~cm}$ na primeira época de amostragem são considerados baixos, exigindo o fornecimento do elemento pelo adubo aplicado. Andrade et al (1975), no mesmo experimento citado anteriormente, observaram que essa cultura extrai do solo cerca de $115 \mathrm{~kg} \mathrm{ha}^{-1}$ de $\mathrm{K}_{2} \mathrm{O}$. Levandose em consideração esses valores, estima-se que a diferença entre o fornecido e o 
extraído resultou em um saldo de aproximadamente $35 \mathrm{~kg} \mathrm{ha}^{-1}$ de $\mathrm{K}_{2} \mathrm{O}$, que possivelmente estão causando a superioridade dos teores de potássio na segunda época de amostragem. Pela comparação dos tratamentos dentro de cada época observou-se que não houve variação significativa dos teores de potássio.

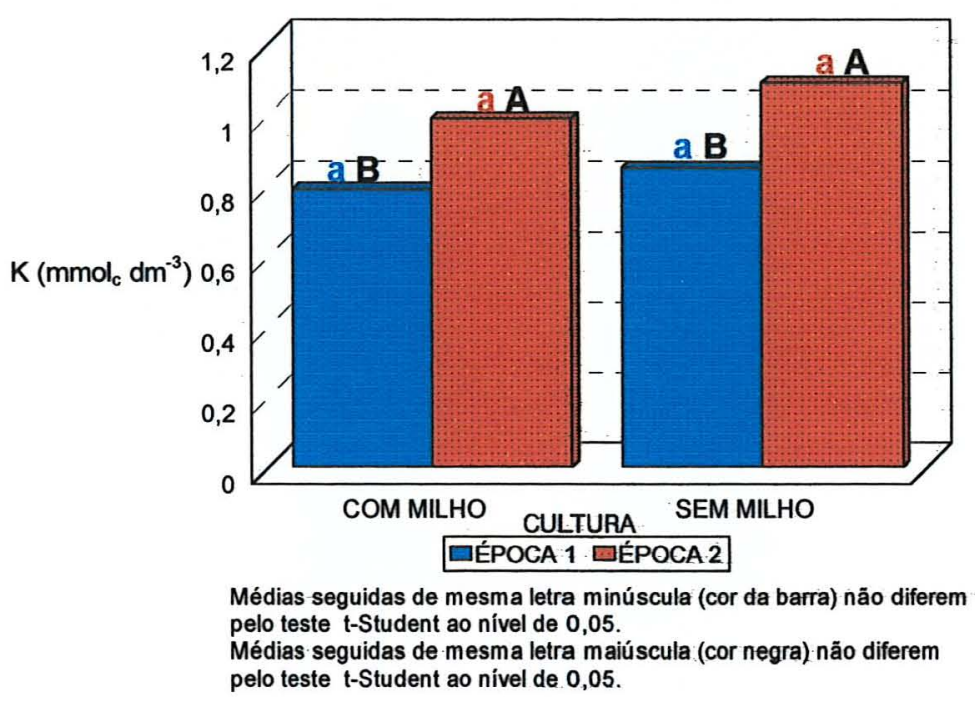

Figura 13 - Potássio na interação época x cultura

\subsubsection{Atributos relacionados à acidez}

A Tabela 8 contém os resultados experimentais para $\mathrm{pH}$, soma de bases, saturação por bases e saturação por alumínio nas interações estudadas.

Os resultados relativos aos atributos relacionados à acidez do solo são apresentados para a interação Época x Profundidade, nas Figuras 14,15 e 16, representando respectivamente, o pH e a saturação por bases, o pH e a soma de bases e o pH e a saturação por alumínio. Os resultados evidenciam que não houve modificação desses atributos quando comparadas as duas épocas estudadas; entretanto, para a análise da variação dos atributos dentro de cada época, nota-se que há uma separação em relação à profundidade do solo. As camadas de $0 \mathrm{a} 20$ cm e de 20 a 40 cm não diferiram estatisticamente, com exceção da saturação por 
alumínio, que se encontra mais elevada na camada de 20 a $40 \mathrm{~cm}$. A maiores profundidades, ou seja, de 40 a $100 \mathrm{~cm}$, os teores em geral não diferiram entre si, mas diferiram das camadas superficiais anteriormente citadas. Para as interações Época x Fertilizante e Época x Cultura não foram evidenciadas variações nos atributos estudados. Os resultados discordam dos obtidos por diversos autores que, estudando a acidificação do solo por adubos nitrogenados, observaram que o sulfato de amônio em geral acidificou o solo em um período curto de tempo, ressaltando-se que esses trabalhos foram sempre desenvolvidos em laboratório sob condições mais controladas do que no campo (Mello \& Andrade, 1973; Kiehl et. al., 1981; Mello e Arzolla, 1983; Mello et. al., 1986; Rosales et al., 1987); entretanto os resultados estão de acordo com o trabalho de Oliveira e Balbino (1995), que avaliaram a acidificação do solo utilizando sulfato de amônio e uréia, sob condições de campo, nas culturas do milho e algodão, observando que o pH nas camadas superficiais só se modificou após 3 anos de cultivo intensivo, ocorrendo a acidificação tanto pela uréia como pelo sulfato de amônio.

A acidificação do solo não ocorreu provavelmente devido a CTC do solo, ver Tabela 1, que conferiu maior poder tampão ao solo tornando mais difícil a ocorrência de variações significativas nos atributos relacionados à acidez do solo.

Os resultados evidenciam a correlação positiva que há entre o $\mathrm{pH}$ e a soma de bases e o $\mathrm{pH}$ e a saturação por bases, ou seja, todos normalmente tendem a diminuir com a profundidade; entretanto, com a saturação por alumínio a correlação é negativa, pois com a diminuição do $\mathrm{pH}$ em profundidade há a elevação desse parâmetro em função da solubilização do alumínio trocável. 
Tabela 8. Atributos relacionados à acidez nas interações estudadas.

\begin{tabular}{|c|c|c|c|c|c|c|c|c|}
\hline \multirow{2}{*}{$\begin{array}{c}\text { FATORES } \\
\text { Profundidade (cm) }\end{array}$} & \multicolumn{2}{|c|}{ ÉPOCA } & \multicolumn{2}{|c|}{ ÉPOCA } & \multicolumn{2}{|c|}{ ÉPOCA } & \multicolumn{2}{|c|}{ ÉPOCA } \\
\hline & 1 & 2 & 1 & 2 & 1 & 2 & 1 & 2 \\
\hline & \multicolumn{2}{|c|}{ pH $\left(\mathrm{CaCl}_{2}\right)$} & \multicolumn{2}{|c|}{$S\left(\mathrm{mmol}_{\mathrm{c}} \mathrm{dm}^{-3}\right)$} & \multicolumn{2}{|c|}{ V(\%) } & \multicolumn{2}{|c|}{ m (\%) } \\
\hline $0-20$ & $4,75 \mathrm{aA}$ & $4,73 \mathrm{aA}$ & 24,34 aA & $22,37 \mathrm{aA}$ & $53,97 \mathrm{aA}$ & $50,33 \mathrm{aA}$ & $2,93 \mathrm{cA}$ & $2,69 \mathrm{cA}$ \\
\hline $20-40$ & $4,64 \mathrm{abA}$ & $4,78 \mathrm{aA}$ & $20,83 \mathrm{abA}$ & $22,85 \mathrm{aA}$ & $48,73 \mathrm{aA}$ & $51,13 \mathrm{aA}$ & $3,90 \mathrm{bcA}$ & $2,85 \mathrm{bcA}$ \\
\hline $40-60$ & $4,50 \mathrm{bA}$ & $4,51 \mathrm{bA}$ & $17,94 \mathrm{bcA}$ & $19,51 \mathrm{abA}$ & $41,17 \mathrm{bA}$ & $44,17 \mathrm{bcA}$ & $7,16 \mathrm{abA}$ & $5,78 \mathrm{abA}$ \\
\hline $60-80$ & $4,44 \mathrm{bA}$ & $4,52 \mathrm{bA}$ & $17,43 \mathrm{bcA}$ & $18,54 \mathrm{bcA}$ & $40,17 \mathrm{bA}$ & $43,03 \mathrm{cA}$ & $8,59 \mathrm{aA}$ & $6,44 \mathrm{aA}$ \\
\hline $80-100$ & $4,47 \mathrm{bA}$ & $4,48 \mathrm{bA}$ & $17,12 \mathrm{cA}$ & $18,51 \mathrm{cA}$ & $40,77 \mathrm{bA}$ & $43,63 \mathrm{cA}$ & $7,22 \mathrm{abA}$ & $6,37 \mathrm{aA}$ \\
\hline
\end{tabular}

\section{Fertilizante}

\begin{tabular}{lcccccccc}
\hline Nitrato de Amônio & $4,53 \mathrm{abA}$ & $4,56 \mathrm{aA}$ & $17,92 \mathrm{bA}$ & $19,43 \mathrm{aA}$ & $42,74 \mathrm{aA}$ & $45,66 \mathrm{aA}$ & $7,36 \mathrm{aA}$ & $5,12 \mathrm{aA}$ \\
\hline Sulfato de Amônio & $4,65 \mathrm{aA}$ & $4,65 \mathrm{aA}$ & $20,75 \mathrm{aA}$ & $21,53 \mathrm{aA}$ & $47,30 \mathrm{aA}$ & $47,94 \mathrm{aA}$ & $4,41 \mathrm{aA}$ & $4,19 \mathrm{aA}$ \\
\hline Sem Nitrogênio & $4,50 \mathrm{bA}$ & $4,59 \mathrm{aA}$ & $19,56 \mathrm{abA}$ & $19,95 \mathrm{aA}$ & $44,84 \mathrm{aA}$ & $45,78 \mathrm{aA}$ & $5,33 \mathrm{aA}$ & $4,39 \mathrm{aA}$
\end{tabular}

\section{Cultura}

\begin{tabular}{lllllllll}
\hline Com & $4,53 \mathrm{aA}$ & $4,58 \mathrm{aA}$ & $18,94 \mathrm{aA}$ & $19,66 \mathrm{aA}$ & $44,39 \mathrm{aA}$ & $45,16 \mathrm{aA}$ & $5,52 \mathrm{aA}$ & $5,08 \mathrm{aA}$ \\
\hline Sem & $4,59 \mathrm{aA}$ & $4,62 \mathrm{aA}$ & $19,84 \mathrm{aA}$ & $20,92 \mathrm{aA}$ & $45,53 \mathrm{aA}$ & $47,76 \mathrm{aA}$ & $5,67 \mathrm{aA}$ & $4,07 \mathrm{aA}$
\end{tabular}

Médias seguidas de mesma letra minúscula (coluna) não diferem pelo teste t-Student ao nível de 0,05

Médias seguidas de mesma letra maiúscula (linha) não diferem pelo teste t-Student ao nível de 0,05 


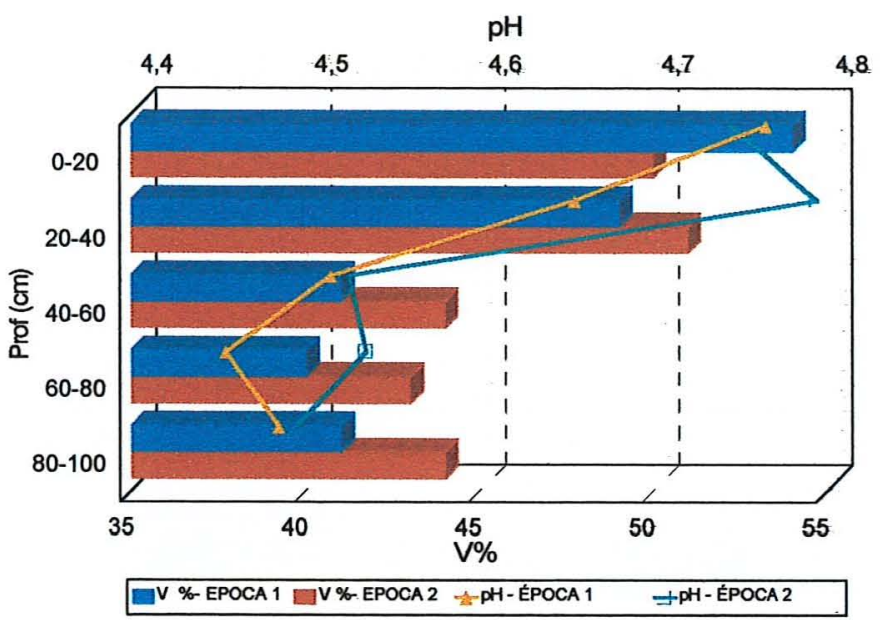

Figura 14 - Saturação por bases e pH ao longo do perfil do solo

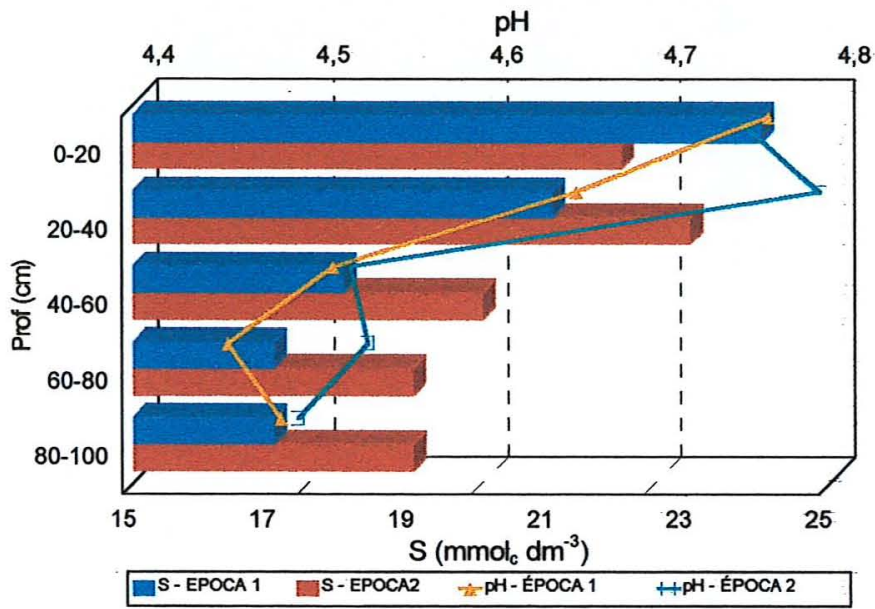

Figura 15 - Soma de bases e $\mathrm{pH}$ ao longo do perfil do solo

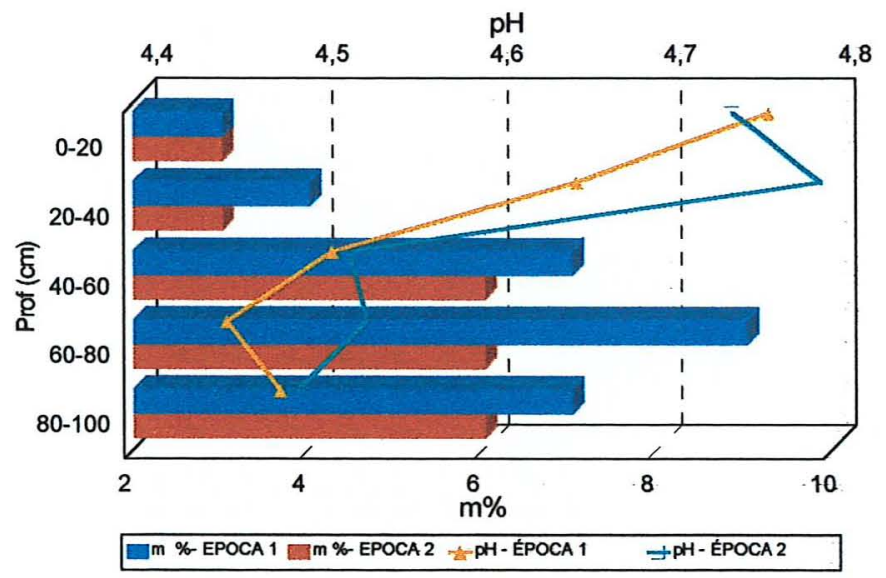

Figura 16 - Saturação por alumínio e pH ao longo do perfil do solo 


\section{CONCLUSÕES}

Os resultados obtidos no presente trabalho permitem as seguintes conclusões:

- A adubação nitrogenada do milho, com nitrato de amônio e/ou sulfato de amônio no Podzólico Vermelho Latossólico incrementou a produção da cultura apesar da adubação verde prévia;

- O nitrato de amônio e o sulfato de amônio apresentaram-se igualmente eficientes no fornecimento de nitrogênio para a cultura do milho;

- As fontes nitrogenadas adotadas não causaram acidificação significativa do solo após uma safra da cultura do milho;

- A utilização do sulfato de amônio resultou em maiores teores de enxofre no solo quando comparado ao nitrato de amônio. 


\section{REFERÊNCIAS BIBLIOGRÁFICAS}

ANDRADE, A.G.; HAAG, H.P.; OLIVEIRA, G.D. de.; SARRUGE, J.R. Acumulação diferencial de nutrientes por cinco cultivares de milho (Zea mays L.). I. Acumulação de macronutrientes. Anais da Escola Superior de Agricultura Luiz de Queiroz, v.32, p.115-149, 1975.

BRADY, N.C. Natureza e propriedades dos solos. 7.ed. Rio de Janeiro: Freitas Bastos, 1989. 898p.

CAJUSTE, L.J. Química de suelos com un enfoque agricola. Chapingo: Colegio de Postgraduados, 1977. 278p.

COUTO, W.; LATHWELL, D.J.; BOULDIN, D.R. Sulfate sorption by two oxisols and an alfisolo of the tropics. Soil Science, v.127, n.2, p.108-116, 1979.

DAL BÓ, M.A.; RIBEIRO,A.C.; COSTA, L.M.; THIEBAUT, J.T.L. Efeito da adição de diferentes fontes de cálcio em colunas de solo cultivada com canade-açúcar. I. Movimentação de bases no solo. Revista Brasileira de Ciência do Solo, v.10, n.3, p.195-198, 1986. 
DERPSCH, R. Alguns resultados sobre adubação verde no Paraná. In: ENCONTRO NACIONAL SOBRE ADUBAÇÃO VERDE, 1., Rio de Janeiro, 1983. Adubação verde no Brasil. Campinas: Fundação Cargill, 1984. p.268279.

ESPINOZA, W.; REIS, A.E.G. dos. Lixiviação em latossolo vermelho escuro de cerrado. II. Magnitude e variabilidade do fenômeno sob irrigação. Pesquisa Agropecuária Brasileira, v.19, n.1, p.85-94, 1984.

FASSBENDER, H.W.; BORNEMISZA, E. Química de suelos com enfasis en suelos de América Latina. 2. ed. San José: IICA, 1987. 420p.

HIROCE, R.; BATAGLIA, O.C.; BAUMGARTNER, J.G.; FURLANI, A.M.C.; MORAES, F.R.P. Efeitos de quatro fontes de adubo nitrogenado nas características químicas do solo e na composição foliar de cafeeiro. Ciência e Cultura, v.29, n.1, p.67-71, 1977.

KANTHACK, R.A.D.;MASCARENHAS, H.A.A.; CASTRO, O.M.; TANAKA, R.T. Nitrogênio aplicado em cobertura no milho após tremoço. Pesquisa Agropecuária Brasileira , v.26, n.1, p.99-104, 1991.

KIEHL, J.C.; MELLO, F.A.F.; ARZOLLA, S. Efeito acidificante de alguns adubos nitrogenados em solos de diferentes texturas. O Solo, v.73, n.7, p.19$24,1981$. 
MAHLER, R.L.; HALVORSON, A. R.; KOEHLER, F.E. Long-term acidification of farmland in northern Idaho and eastern Washington. Comunications in Soil Science and Plant Analysis, v.16, n.1, p.83-95, 1985.

MELLO, F.A.F.; ANDRADE, R.G. de A influência de alguns adubos nitrogenados sobre o $\mathrm{pH}$ do solo. Revista da Agricultura, v.48, n.2-3, p.6978, 1973.

MELLO, F.A.F.; ARZOLLA, S. Acidificação do solo por adubos nitrogenados. Efeitos residuais após a primeira e segunda colheita. Revista da Agricultura, v.58, n.4, p.17-24, 1983.

MELLO, F.A.F.; POSSIDIO, E.L.; PEREIRA, J.R. ARAÚJO, J.P.; ABRAMOF, L.; COSTA, O.A. Efeito acidificante da uréia e do sulfato de amônio em latossolo vermelho escuro. Revista da Agricultura, v.61, n.3, p.291-296, 1986.

MORAES, F.R.P. Efeito de alguns fertilizantes nitrogenados sobre o $\mathrm{pH}$ do solo e a concentração de alumínio e manganês nas folhas de cafeeiros. In: CONGRESSO BRASILEIRO SOBRE PESQUISAS CAFEEIRAS, 2., Poços de Caldas, 1974. Resumos. Brasília: EMBRAPA, 1974. p.279-280.

MUZILLI, O.; OLIVEIRA, E.L.; GERAGE, A.C.; TORNERO, M.T. Adubação nitrogenada em milho no Paraná. III. Influência da recuperação do solo com adubação verde de inverno nas respostas à adubação nitrogenada. Pesquisa Agropecuária Brasileira , v.18, n.1, p.23-27, 1983. 
NEVES, O.S.; VIEGAS, G.P.; FREIRE, E.S. Efeito do uso contínuo de certos adubos azotados sobre o pH do solo. Bragantia, v.19, n.46, p.125-132, 1960.

OBI, A.O. Long-term effects of the continuous cultivation of a tropical ultisol in southwestern Nigéria. Experimental Agriculture; v.25, n.2, p.207-215, 1989.

OLIVEIRA, E.F. de; BALBINO, L.C. Efeitos de fontes e doses de nitrogênio aplicados em cobertura nas culturas de trigo, milho e algodão. Resultados de Pesquisa OCEPAR, n.1, p.7-39, 1995.

QUAGGIO, J.A. Reação do solo e seu controle. In: SIMPÓSIO AVANÇADO DE QUÍMICA E FERTILIDADE DO SOLO, Piracicaba, 1986. Anais. Campinas: Fundação Cargill, 1986. p.53-89.

QUEVEDO CAMACHO, J.C. Efeito do balanço de cátions e ânions da planta na acidificação do solo por fertilizantes nitrogenados. Piracicaba, 1995. 106p. Dissertação (Mestrado) - Escola Superior de Agricultura "Luiz de Queiroz", Universidade de São Paulo.

RAIJ, B. van. Fertilidade do solo e adubação. Piracicaba: POTAFOS; São Paulo: Ceres, 1991. 343p.

RAIJ, B. van.; QUAGGIO, J.A.; CANTARELLA, H.; FERREIRA, M.E.; LOPES, A.S.; BATAGLIA, O.C. Análise química do solo para fins de fertilidade. Campinas: Fundação Cargill, 1987. 170p. 
RAIJ, B. van. Propriedades eletroquímicas de solo. In: SIMPÓSIO AVANÇADO DE QUÍMICA E FERTILIDADE DO SOLO, Piracicaba, 1986. Anais. Campinas: Fundação Cargill, 1986. p.9-42.

RAIJ, B. van; CANTARELLA, H.; CAMARGO, A.P.; SOARES, E. Perdas de cálcio e magnésio durante cinco anos em ensaio de calagem. Revista Brasileira de Ciência do Solo, v.6, n.1, p.33-37, 1982.

RASMUSSEN, P.E.; ROHDE, C.R. Soil acidification from ammonium-nitrogen fertilization in moldbourd plow and stubble-mulch wheat-fallow tillage. Soil Science Society of America Journal, v.53, n.1, p.119-122, 1989.

REICHARDT, K. Dinâmica de íons no solo. In: SIMPÓSIO AVANÇADO DE QUIMICA E FERTILIDADE DO SOLO, Piracicaba, 1986. Anais. Campinas: Fundação Cargill, 1986. p. 43-51.

RITCHEY, K.D.; SOUZA, D.M.G.de; LOBATO, E.; CORREA, O. Calcium leaching to increase rooting depth in a Brazilian Savannah oxisol. Agronomy Journal, v.72, n.1, p.40-44, 1980.

ROSALES M.P.; MELLO, F.A.F., ARZOLLA, S.; THOMASI, M.D.. Efeito residual de alguns adubos nitrogenados sobre algumas características químicas de um solo. Anais da Escola Superior de Agricultura "Luiz de Queiroz", v.44, n.2, p.927-957, 1987.

SÁNCHEZ, P.A. Suelos del tropico: características y manejo. San José: IICA, 1981. $660 \mathrm{p}$. 
SOUZA, D.M.G. de; RITCHEY, K.D. Correção de acidez sub-superficial: uso de gesso no solo de cerrado. In: SIMPÓSIO AVANÇADO DE QUÍMICA E FERTILIDADE DO SOLO, Piracicaba, 1986. Anais. Campinas: Fundação Cargill, 1986. p. 91-113.

STUMPE, J.M; VLEK, P.L.G. Acidification induced by different nitrogen sources in columns of selected tropical soil. Soil Science Society of America Journal; v.55, n.1, p.145-151, 1991.

VITTI, G. C. Avaliação e interpretação do enxofre no solo e na planta. Jaboticabal: FUNEP, 1989. 37p.

VITTI, G.C.; PROCHNOW, L.I. Curso de nutrição mineral de plantas. Brasília: ABEAS, 1996. 58p. (ABEAS. Curso de Especialização por Tutoria à Distância. Módulo 3: Corretivos - calcário e gesso: características, métodos de recomendação e uso; Módulo 4: Adubos: obtenção, características e uso.).

WOLCOTT, A.R.; FOTH, H.D.; DAVIS, J.F.; SHICKLUNA, J.C. Nitrogen carriers: I. Soil effects. Soil Science Society of America Proceedings, v.29, n.4, p.405-410, 1965.

WUTKE, E.B. Adubação verde: manejo da fitomassa e espécies utilizadas no Estado de São Paulo. In: CURSO SOBRE ADUBAÇÃO VERDE NO INSTITUTO AGRONÔMICO, 1., Campinas, 1993. Documentos IAC, n.35, p.17-29, 1993. 